\title{
Influence of Unsteady Flow Induced by a Large-Scale Hydropower Station on the Water Level Fluctuation of Multi-Approach Channels: A Case Study of the Three Gorges Project, China
}

\author{
Zhiyong Wan ${ }^{1,2} \oplus$, Yun $\mathrm{Li}^{1,2, *}$, Xiaogang Wang ${ }^{2, *}$, Jianfeng An ${ }^{2}$, Bo Dong ${ }^{2,3}$ and Yipeng Liao ${ }^{2,4}$ \\ 1 School of Water Resources and Hydropower Engineering, Wuhan University, Wuhan 430072, China; \\ wanyhrac_cn@126.com \\ 2 State Key Laboratory of Hydrology-Water Resources and Hydraulic Engineering, Nanjing Hydraulic \\ Research Institute, Nanjing 210029, China; jfan@nhri.cn (J.A.); dongbo@nsy.com.cn (B.D.); \\ crocodilence@163.com (Y.L.) \\ 3 Nanjing Automation Institute of Water Conservancy and Hydrology, Nanjing 210012, China \\ 4 College of Water Conservancy and Hydropower Engineering, Hohai University, Nanjing 210098, China \\ * Correspondence: yli@nhri.cn (Y.L.); xgwang@nhri.cn (X.W.); Tel.: +86-025-8582-8298 (X.W.)
}

Received: 28 September 2020; Accepted: 16 October 2020; Published: 19 October 2020

check for updates

\begin{abstract}
Unsteady flow induced by hydropower stations exerts a significant impact on the water level in multi-approach channels, which directly threatens the safe passage of ships. In this study, a one-dimensional and a two-dimensional hydrodynamic model are adopted to simulate the water level fluctuations at the entrance of multi-approach channels and the lower lock head of a ship lift with consideration of initial water surface elevation, base flow, flow amplitude, regulation time, and locations of hydropower stations, unfavorable conditions are successfully identified; and the fluctuations at the approach channel entrance and the lower lock head of a ship lift under single-peak and double-peak regulating mode are analyzed considering the flow regulating of the Gezhouba Hydropower Station (GHS), thus, the water level oscillation process in the multi-approach channels is presented. Results show that the largest wave amplitude in the multi-approach channels manifests under unfavorable conditions including lower initial water surface elevation, smaller base flow, larger flow variation, and shorter regulation time; and water level fluctuation in the multi-approach channel is primarily induced by flow amplitude and net flow between the Three Gorges Hydropower Station (TGHS) and the GHS, with consideration of the counter-regulation process of the GHS. This research contributes to providing a reference for a similar large-scale cascade hydropower station regarding regulation and control of navigation conditions.
\end{abstract}

Keywords: inland navigation; multi-approach channels; unsteady flow; water level fluctuation; hydropower station

\section{Introduction}

Inland waterways are a crucial part of the domestic transportation network in many countries, such as Europe, the United States, and China [1-4]. In the navigation domain, unsteady flow in the locks approach channel $[5,6]$ is the ubiquitous flow in the shallow waterway, which can generate a considerable influence on downstream navigation, water supply, and sediment transport $[7,8]$. In recent years, numerous site-specific studies have been conducted that supported development of navigation on a nation's inland waterways, due to an increased demand for inland waterway shipping [9,10], especially, the gradual rebuilding or expanding of previous single way locks. Currently, an increase in multi-line 
locks is prevalant in China, and the unsteady hydrodynamics problem of the common approach channel of multi-line locks is becoming increasingly complicated and varied among actual engineering situations. Nevertheless, hydraulic factors in approach channels related to topographic boundary conditions, lock approach configurations, and the operation mode of hydro-junction scheduling, inevitably pose a great threat to shipping safety or berthing of ships. To be specific, the water depth in an approach channel is insufficient if the water level fluctuates greatly, which can scrape the bottom of a ship [11], or can break the ship's cables because of an excessive mooring force, such as the No. 2 and No. 3 approach channels at the Gezhouba shipping lock, in China. Consequently, unsteady flow navigation conditions in an approach channel drastically impact the functional efficiency and safety of any given multi-line lock.

To investigate navigation conditions in lock approaches, the Jim Woodruff Dam was one of the earliest models studied which indicated the superiority of slotted walls for reducing the lateral flow intensity of lock approaches [12], and then the navigation conditions at Maxwell Locks and Dam, Monongahela River, as well as Melvin Price Locks and Dam, Mississippi River were investigated in sequence [13-15]. Afterwards, numerous research findings from domestic and foreign scholars considered that the navigation conditions in the approach channel were closely consistent with the operation of dams, hydropower stations, as well as locks. For instance, Maeck et al. [16] investigated the effects of upstream and downstream ship locks on the water level and current dynamics in a $12.9 \mathrm{~km}$ long basin of an impounded river (Saar, Germany).

Nowadays, more and more hydropower stations have been put into operation in the world [17]. Hydropower that is derived from the energy of flowing water is a renewable and sustainable energy source which plays an indispensable role in the global electricity grid system [18], because of the importance of developing renewable energy sources to achieve sustainability goals. The development of large hydropower plants is closely connected with high economic, environmental, and social costs despite evolving viewpoints concerning the sustainability of large hydropower installations $[19,20]$. Moreover, many scholars have conducted numerous studies related to environmental flows [21-23] and energy-ecosystem regulation for sustainable hydropower stations [20], and these findings have contributed to an understanding of the importance of a riverine ecosystem and have helped to provide a basis for renewable energy sources development. Nevertheless, the operation of a hydropower station is associated with alterations of a riverine ecosystem and it is also connected to the navigation conditions for ships which transport cargoes from cities to remote regions. Furthermore, the effect of the operation of hydropower stations on navigation conditions has always been an extremely important research subject in the navigation domain. For example, Bravo et al. [24] investigated flow fields and navigation conditions induced by a hydropower plant releasing into a lower lock approach, and developed criteria for acceptable navigation conditions based on steady-state and transient tests. In China, physical model tests and mathematical models are utilized to investigate the navigation conditions in terms of hydropower station operation. Li et al. [25] and Yang et al. [26] carried out special experimental research to demonstrate and optimize various regulation schemes concerning the influence of the TGHS daily load regulations on the waterway navigation between the Three Gorges Dam (TGD) and the Gezhouba Dam (GZD); Zhao et al. [27] conducted preliminary research with a physical model on daily regulation during a low-flow season and demonstrated that unsteady flow had a strong influence on navigation conditions. Nevertheless, it is not economical or convenient to conduct physical model tests for research on navigation conditions, and therefore more details from model tests may not be captured. Hence, Shang et al. [28] established a one-dimensional (1D) hydrodynamic model to simulate the influence of the daily regulation of the Xiaonanhai hydropower station on downstream navigation, and then proposed a practical method for evaluating the navigability of the small and midsize hydropower stations; some additional studies [29] have asserted that it would be better to deliberate throughout the dry season during the daily regulation of a hydropower station. Furthermore, Jia et al. [30] proposed a navigability evaluation method for an approach 
channel by considering the variation of flow velocity and water level, based on a two-dimensional (2D) mathematical model.

As mentioned in the literature review, unsteady flow is generated from hydropower stations and it is a complicated process in the channels. In particular, unsteady flow is regarded to be the result of interaction consequences of boundaries (e.g., river bands, closed ends, and branches) from approach channels and hydro-junction regulations (e.g., dams, locks, and power plants). Prior studies have focused more on the analysis of the velocity and hydraulic gradient in a single way lock approach. However, larger water level fluctuation is transmitted by downstream approach channels and may inevitably affect the safe navigation of ships because of a sudden rise or fall in the water level. Currently, few studies have been conducted on extremely large-scale multi-approach channels with complex flow confluence, wave propagation, and superposition. In addition, water level fluctuations in narrow branched and common multi-approach channels under the regulation of cascade hydropower stations, so far, have not been investigated further, especially the multi-approach channels of a multi-line giant lock. The innovative contribution of this study lies in the water level fluctuation analysis under different factors including initial water surface elevation, base flow, flow amplitude, regulation time, and locations of large-scale hydropower stations, particularly in the multi-approach channels, and therefore revealing the wave oscillation process in multi-approach channels considering the counter-regulation process of the GHS so as to have a better knowledge of the navigation conditions of the multi-approach channels.

To alleviate the increased demand for shipping volume on the Yangtze River, it is planned to introduce a new channel on the left bank of the Three Gorges ship lock which constitutes the complicated navigation routes where the approach channels of the ship lift, the existing lock, and the planned lock meet. The layout of multi-approach channels is infrequent in the world, hence, taking the Three Gorges multi-approach channels as a case study, the main objectives of this study are the following: (i) To reveal the water level fluctuations at the entrance of the multi-approach channels and the lower lock head of a ship lift with consideration of initial water surface elevation, base flow, flow amplitude, regulation time, and locations of hydropower stations. (ii) To identify the most unfavorable operating conditions for navigation, thereby providing available recommendations for the TGHS regulations. (iii) To present the water level oscillation process in a multi-approach channel and obtain the main influence factors considering the counter-regulation process of the GHS. This paper is structured as follows: In Section 2, we explain the details of study area and establish a 1D and a 2D model validated by the measured data; in Section 3, we describe the analysis of the water level fluctuation at the entrance of the multi-approach channels and the lower lock head of the ship lift induced by variables concerning initial surface water elevation, base flow, flow amplitude, regulation time, as well as locations of hydropower station, and we discuss our investigation of the water level fluctuation processes under the single-peak and the double-peak regulations, concerning the peak-shaving mode of a TGHS and GHS cascade hydropower station; in Section 4, we present and discuss our main results; and finally, the main conclusions drawn from this study are presented in Section 5.

During the unsteady flow investigation of the multi-line lock approaches, concern was expressed over the variation of water surface elevation for the huge navigation projects located downstream from the Three Gorges Project (TGP). We attempt to address this concern based on the data collected and using the numerical techniques adopted for the investigation.

\section{Materials and Methodology}

\subsection{Overview of the Study Area}

\subsubsection{Description of the Three Gorges Project Navigation Structures}

The navigation structures of the Three Gorges Project (TGP) are composed of a vertical ship lift and a dual-line five-step continuous ship lock, which are all arranged on the left bank. The approach channel of the ship lift merges into the approach channel around $1100 \mathrm{~m}$ downstream of the lock 
head, and then enters the main channel of the Yangtze River. The bottom width of the downstream approach channel, after the confluence of the two approach channels, is approximately $180-220 \mathrm{~m}$, the entrance width of the approach channel is $200 \mathrm{~m}$, and the elevation of the bottom is $56.5 \mathrm{~m}$. Moreover, the downstream approach channel of the ship lift is located on the beachside of the convex bank along the left bank of the dam downstream bend. The angle between the centerline of the channel and dam axis is $80^{\circ}$, the bottom width of the approach channel is approximately $80-90 \mathrm{~m}$, the length is approximately $2700 \mathrm{~m}$, and the elevation of the bottom is approximately $58.0 \mathrm{~m}$. The downstream approach channel is also equipped with a water-dividing dike (distance $=2722 \mathrm{~m}$ ), with an elevation of $78 \mathrm{~m}$ at the upper section and an elevation of $76 \mathrm{~m}$ at the lower section of the water-dividing dike.

The volume of cargo on the mainstream of the Yangtze River has been increasing over the past decade, and the existing lock and ship lift are unable to meet the future demand for waterborne cargo. To alleviate the growing demand for navigation and to bring into full play the role of the Yangtze River Golden Waterway [31], it has been proposed to plan a new access route on the left bank of the Three Gorges Project (TGP) to meet the shipping demand. The upstream inlet of the route is located at the Lujia river bank wharf along with the upstream of the new Taiping Creek town, and the downstream outlet is about $1 \mathrm{~km}$ from the upstream of the heavy-equipment dock at Bahekou Station, with a total length of $5123 \mathrm{~m}$. Below the entrance of the upstream lock is a straight line with a length of $4003 \mathrm{~m}$, the direction of which is at an angle of approximately $4^{\circ}$ with the centerline of existing locks; the distance between them is around $800-1000 \mathrm{~m}$. The downstream of the straight-line section is, first, connected with a radius of $1000 \mathrm{~m}$, as well as a centroid angle of $48^{\circ}$, and then it connects to the Yangtze River by a tangent of arc. The route of the outlet section is parallel to the planned route outside the entrance of the downstream approach channel. The arrangement of the TGP is depicted in Figure 1a,b.

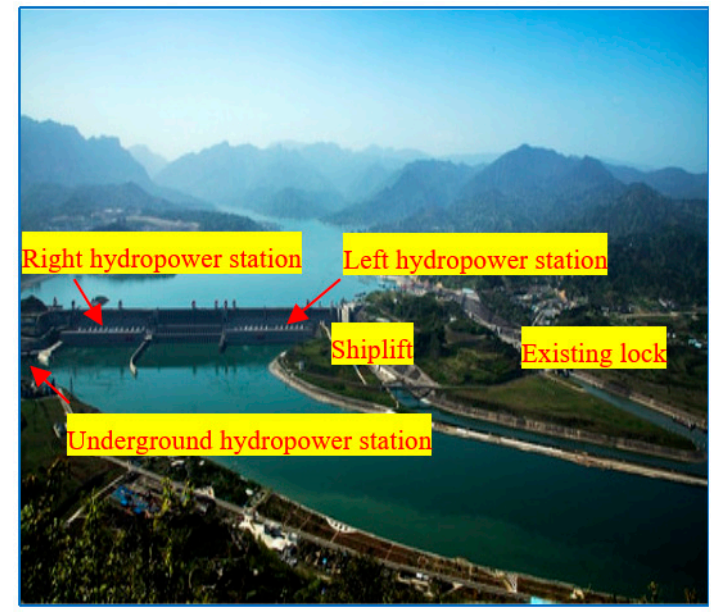

(a)

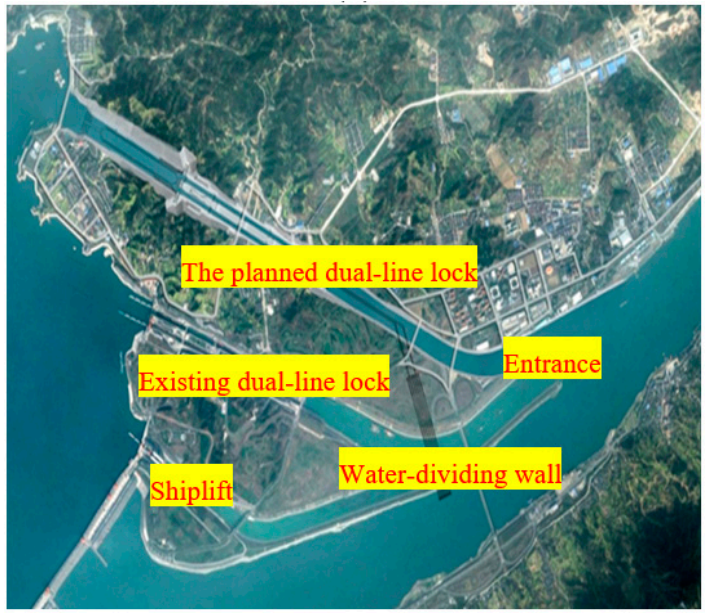

(b)

Figure 1. The layout of the Three Gorges Project (TGP). (a) View of the downstream of the existing TGP; (b) Layout of the planned lock for the TGP.

\subsubsection{Characteristics of the Reach between the Three Gorges Dam (TGD) and the Gezhouba Dam (GZD)}

Combined with the available topographic data derived from a 1:1000 topographic map of the channel, measured in 2012, the reach between the TGD and GZD is characterized as follows:

The reach from the TGD axis to Letian creek is a wide valley section approximately $9.6 \mathrm{~km}$ in length; the upper is a bend and its river channel is a compound section, and the talweg directs to the right bank. The lower Letian creek bend has a straight section which is a wide valley section along the two bends; the river width can reach $1400 \mathrm{~m}$ during the flood season, whereas the breadth of the entire river is generally 150-250 m during the dry season. The reach from Letian Creek to Nanjinguan Station is located at Xiling Canyon, and is $26.49 \mathrm{~km}$ long with a water surface width of $300-400 \mathrm{~m}$. From the 
upstream to the downstream reach of the river section, the river reach has several bends such as Letian Creek, Liantuo, Shipai, and Nanjinguan with a turning angle of nearly $90^{\circ}$. The narrow valley section has meandering and twisting steep banks, narrow and deep river channel, and the cross-section is presented as a "U-shape" or "V-shape". The elevation of the riverbed fluctuates frequently, as well as violently, showing jagged changes and even reaches $-40 \mathrm{~m}$; the sharp river bends flow rapidly during flood season and the flow pattern becomes turbulent. In addition, the reach from Nanjinguan to GZD is $2.3 \mathrm{~km}$ long, and the river widens from 300 to $2500 \mathrm{~m}$. In particular, the reach between the TGD and GZD is always in the backwater area since the GZD impounding, and most beach sections, to some extent, are inundated, thereby improving the navigation conditions between the TGD and GZD. The reach of the reservoir area is balanced by sediment flushing and deposition after nearly ten years of riverbed evolution. The layout of the channel between the TGD and GZD is sketched in Figure 2.

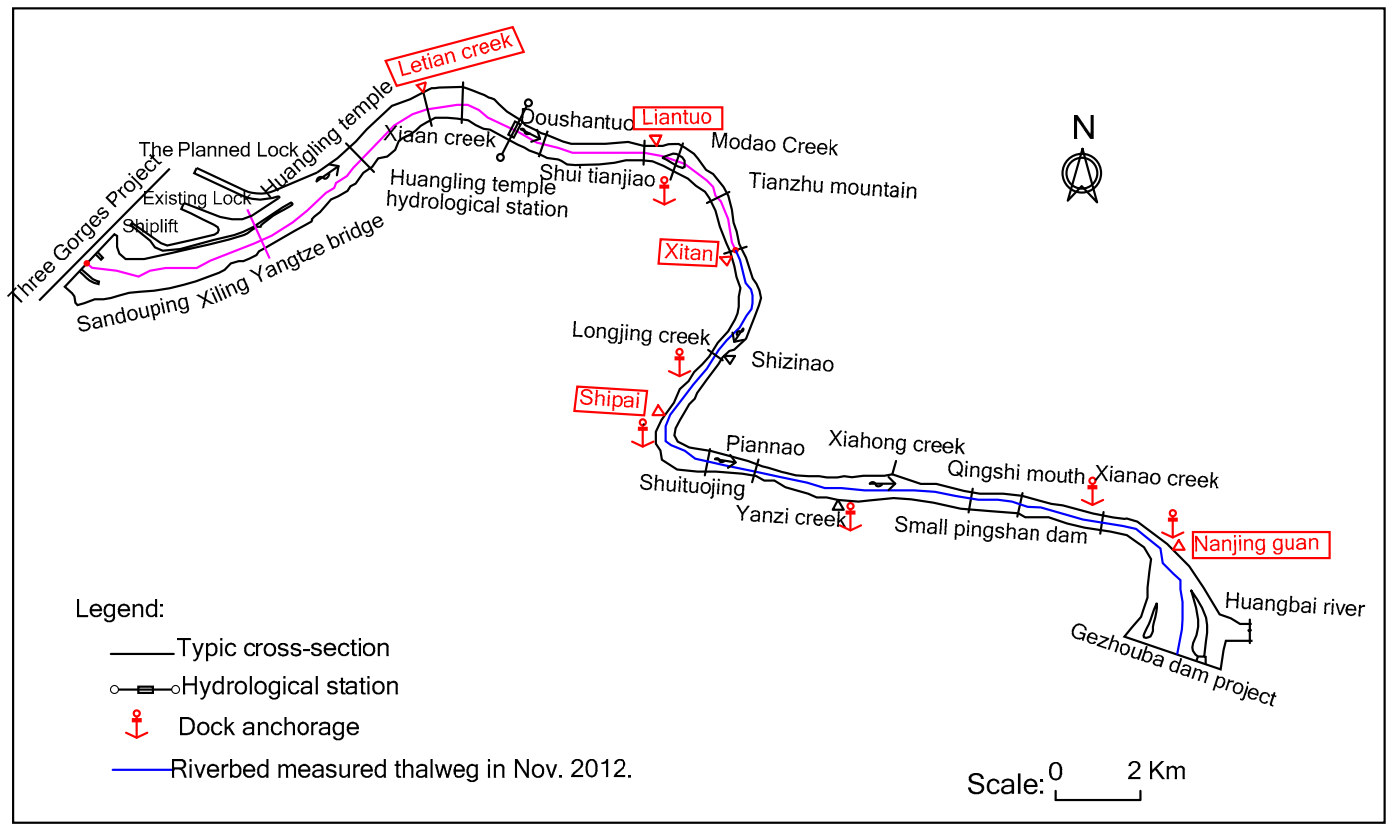

Figure 2. Schematic of river channel between the Three Gorges Dam (TGD) and the Gezhouba Dam (GZD).

Combining the measured topography data between the TGD and GZD, on the one hand, Letian Creek and Liantuo river bends have a strong influence on the longwave reflection of the channel, thus the lower boundary of the calculation model is not close to the GZD and TGD. On the other hand, the scale effect of an existing physical model and the limitations of the planned physical model test site are considered to be comprehensive, and a calculation domain regarding the $2 \mathrm{D}$ hydrodynamic model approximately $19.5 \mathrm{~km}$ from TGD to Xitan Station turns out to be reasonable.

\subsection{Hydrodynamic Model}

To identify the unsteady flow in a long reach, a one-dimensional mathematical model is accurate for determining water level and flow at each section; whereas a 2D model is adopted to identify the water level for a short reach, and its calculation accuracy can meet the engineering requirements. Next, we describe the mathematical models, respectively.

\subsubsection{One-Dimensional Hydrodynamic Model}

Assuming that the water is incompressible and homogeneous, the bottom slope is small and the wavelengths are large in contrast to the water depth, given the long distance (around $38.0 \mathrm{~km}$ ) between the TGD and GZD, one-dimensional shallow water hydrodynamic in open channel flow between the 
TGD and GZD is simulated using the St. Venant system of equations of continuity and momentum, which, respectively, are:

$$
\begin{gathered}
\frac{\partial Q}{\partial x}+B \frac{\partial Z}{\partial t}=q \\
\frac{\partial Q}{\partial t}+\frac{\partial\left(\alpha Q^{2} / A\right)}{\partial x}+g A \frac{\partial Z}{\partial x}+\frac{g Q|Q|}{C^{2} A R}=0
\end{gathered}
$$

where $x$ is the coordinates along river length, $\mathrm{m}$; $t$ represents time, $\mathrm{s} ; Q$ represents the discharge, $\mathrm{m}^{3} / \mathrm{s}$; $q$ represents the discharge flowing into or out of the river channel per unit length along the way (e.g., source or sink), $\mathrm{m}^{2} / \mathrm{s} ; g$ represents gravity acceleration, $\mathrm{m} / \mathrm{s}^{2} ; A$ represents the flow area, $\mathrm{m}^{2}$; $B$ represents the river width, $\mathrm{m} ; Z$ represents the water level, $\mathrm{m} ; R$ denotes the hydraulic radius, $\mathrm{m}$; $C$ denotes the Chezy resistance coefficient; and $\alpha$ represents the momentum distribution coefficient.

\subsubsection{Two-Dimensional Depth-Averaged Shallow Water Model}

Governing equations for the depth-averaged model, also known as shallow water for approach channel flow, are derived by depth-averaging the Reynolds-averaged mass and momentum conservation with the assumption of hydrostatic pressure distribution and negligible vertical acceleration [32]. Considering the actual downstream topography and flow characteristics of the TGD, the incompressible two-dimensional (2D) shallow water equation with integral over depth is adopted to simulate the changes of water level and flow owing to the various boundary conditions, and the continuity and momentum equations are as follows:

Continuity equation :

$$
\frac{\partial h}{\partial t}+\frac{\partial h \bar{u}}{\partial x}+\frac{\partial h \bar{v}}{\partial y}=h S
$$

Momentum equations:

$$
\begin{gathered}
\frac{\partial h \bar{u}}{\partial t}+\frac{\partial h \bar{u}^{2}}{\partial x}+\frac{\partial h \overline{u v}}{\partial y}=f \bar{v} h-g h \frac{\partial \eta}{\partial x}-\frac{h \partial p_{\alpha}}{\rho_{0} \partial x}-\frac{g h^{2} \partial \rho}{2 \rho_{0} \partial x}+\frac{\tau_{s x}-\tau_{b x}}{\rho_{0}}- \\
\frac{1}{\rho_{0}}\left(\frac{\partial s_{x x}}{\partial x}+\frac{\partial s_{x y}}{\partial y}\right)+\frac{\partial}{\partial x}\left(h T_{x x}\right)+\frac{\partial}{\partial y}\left(h T_{x y}\right)+h u_{S} S \\
\frac{\partial h \bar{v}}{\partial t}+\frac{\partial h \bar{v}^{2}}{\partial y}+\frac{\partial h \overline{u v}}{\partial x}=f \bar{u} h-g h \frac{\partial \eta}{\partial y}-\frac{h \partial p_{\alpha}}{\rho_{0} \partial y}-\frac{g h^{2} \partial \rho}{2 \rho_{0} \partial y}+\frac{\tau_{s y}-\tau_{b y}}{\rho_{0}}- \\
\frac{1}{\rho_{0}}\left(\frac{\partial s_{y x}}{\partial x}+\frac{\partial s_{y y}}{\partial y}\right)+\frac{\partial}{\partial x}\left(h T_{x y}\right)+\frac{\partial}{\partial y}\left(h T_{y y}\right)+h v_{s} S
\end{gathered}
$$

where $x, y$, and $z$ are the Cartesian coordinates, $\mathrm{m} ; u$ and $v$ are the velocity components in the direction of $x$ and $y, \mathrm{~m} / \mathrm{s} ; \bar{u}$ and $\bar{v}$ are the average velocity components in the $x$ and $y$ direction, $\mathrm{m} / \mathrm{s} ; t$ represents time, $\mathrm{s} ; \eta$ is the bottom elevation, $\mathrm{m}$; $d$ is the water depth, $\mathrm{m} ; h=\eta+d$ is the total water depth, $\mathrm{m} ; g$ is the gravitational acceleration, $\mathrm{m} / \mathrm{s}^{2} ; f=2 \omega \sin \varphi$ is the Coriolis parameter ( $\omega$ denotes the angular rate of revolution and $\varphi$ denotes the geographic latitude), $\mathrm{s}^{-1} ; \rho$ is the water density, $\mathrm{kg} / \mathrm{m}^{3} ; \rho_{0}$ is the reference water density, $\mathrm{kg} / \mathrm{m}^{3} ; s_{x x}, s_{x y}, s_{y x}$, and $s_{y y}$ are components of the radiation stress tensor, $\mathrm{kg} / \mathrm{s}^{2} ; \tau_{s x}$ and $\tau_{s y}$ are the surface stress, $\mathrm{kg} / \mathrm{s}^{2} \cdot \mathrm{m} ; \tau_{b x}$ and $\tau_{b y}$ denote the bottom stress, $\mathrm{kg} / \mathrm{s}^{2} \cdot \mathrm{m} ; p_{a}$ denotes atmospheric pressure, $\mathrm{kg} / \mathrm{s}^{2} \cdot \mathrm{m} ; S$ represents the magnitude of the discharge due to point sources, $\mathrm{s}^{-1} ; u_{s}$ and $v_{s}$ are the flow velocity of source and sink, $\mathrm{m} / \mathrm{s} ; T_{x x}, T_{x y}$, and $T_{y y}$ represent the lateral stresses, $\mathrm{m}^{2} / \mathrm{s}^{2}$, which are estimated, respectively, using an eddy viscosity formulation; $E$ represents the horizontal eddy viscosity coefficient, $\mathrm{m}^{2} / \mathrm{s}$.

$$
T_{x x}=2 E \frac{\partial \bar{u}}{\partial x}, T_{x y}=E\left(\frac{\partial \bar{u}}{\partial y}+\frac{\partial \bar{v}}{\partial x}\right), T_{y y}=2 E \frac{\partial \bar{v}}{\partial y}
$$

The finite volume method is herein utilized to discrete the two-dimensional shallow water equation over depth within the computational domain. The two-stage TVD Runge-Kutta method is utilized to solve the formulas in the model [33,34]. 
In this study, a one-dimensional model and a 2D numerical model are combined to diagnose the navigation conditions for the multi-approach channels, the one-dimensional model, in this study, is utilized to provide water level boundary conditions at the Xitan Station for the 2D depth-averaged shallow water model. Generally, the methodology in this study is adopted to obtain water level fluctuations in the approach channels, however, limitations exist by considering merely the water-level range as a navigation constraint of the mathematical model and using a $2 \mathrm{D}$ depth-averaged model without considering the vertical distribution effects. A flowchart of the analysis conducted in this study is presented in Figure 3.

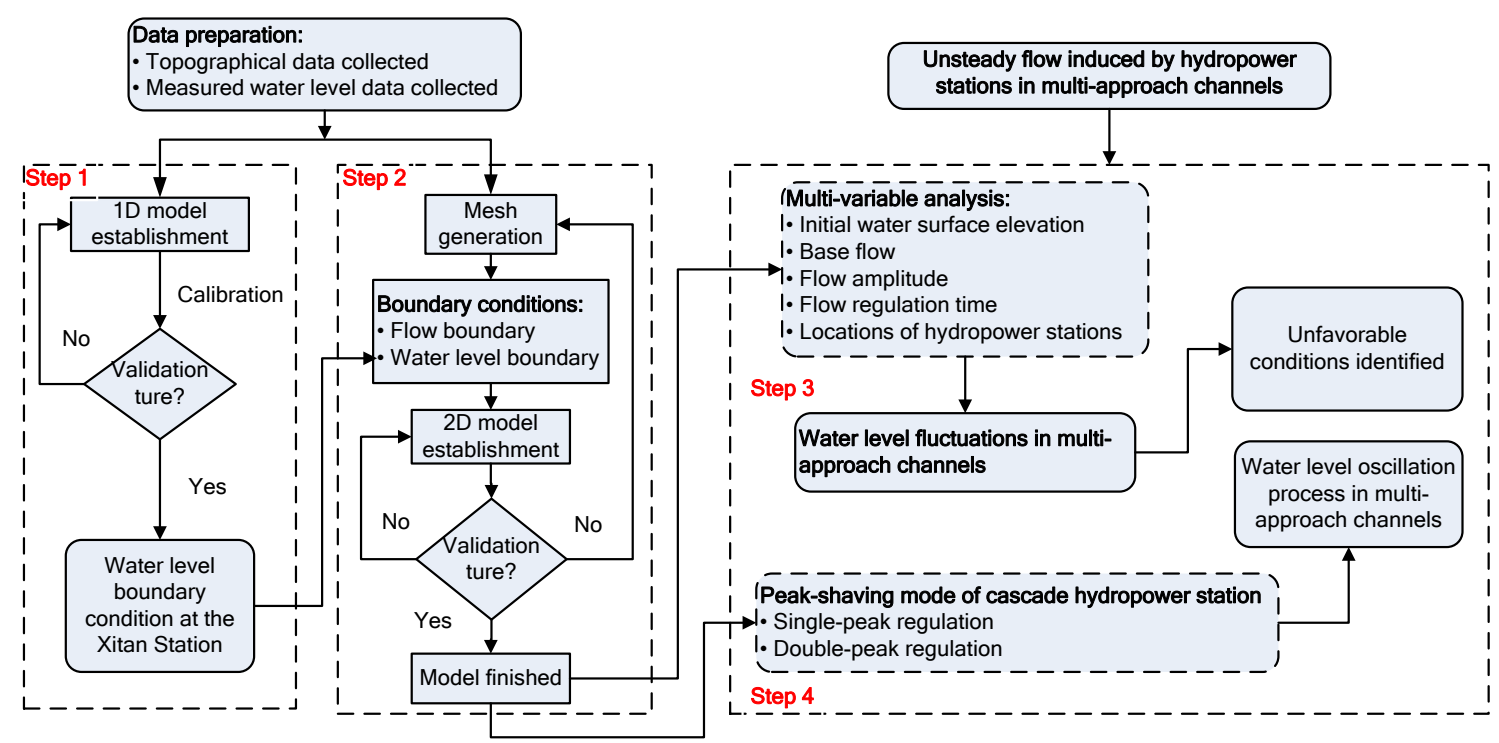

Figure 3. The flowchart of the analysis conducted in this study.

\subsection{Model Establishment and Validation}

In this section, we establish a one-dimensional and a 2D mathematical model based on shallow water theory along with model validation conducted by comparing simulation results with prototype observation and physical model test upon unsteady flow.

\subsubsection{Mesh Generation}

The study area simulated by the $2 \mathrm{D}$ mathematical model is a $19.5 \mathrm{~km}$ long downstream reach from the TGD. On the basis of the topographic characteristics of the channel downstream of TGP, the existing lock approach, the ship lift approach, and the planned approach were gridded using an unstructured mesh. The mesh size varied, along with the breadth of the channel. In particular, the mesh in areas where there was a large gradient of topography was locally encrypted, the mesh scale of the multi-approach channel was around 4-7 m, the total number of elements was 126,000 within the entire computation domain. The mesh division of the computation domain (TGD-Xitan) is shown in Figure 4. 


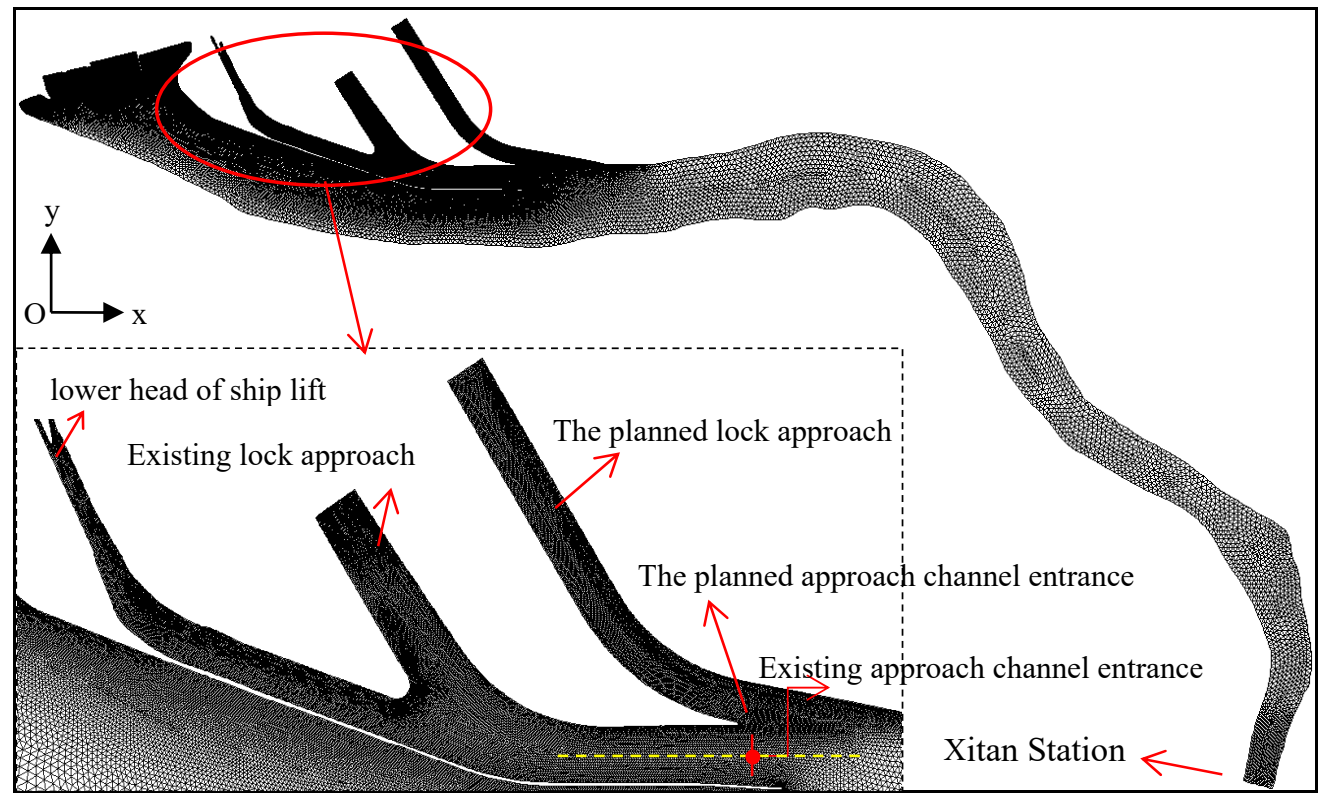

Figure 4. Computation domain and mesh generation.

\subsubsection{Boundary Conditions}

To identify the navigation condition in the multi-approach channel downstream of the TGP, it was vital to examine the properties of the study area and set boundary conditions. Boundary conditions used in the current model were as follows: (i) The downstream boundary of the TGP was the flow, the lower lock head of the ship lift and the ship lock were set as the closed boundaries, and the water level boundary at the Xitan Station within the calculation domain was determined via a one-dimensional mathematical model. (ii) The TGHS was regarded as the flow boundary, the Xitan Station was set as the water level boundary given by a one-dimensional model, and the rest were set as the land boundaries. Along closed boundaries, normal fluxes were forced to zero for all variables. In particular, for beaches within the study area that rise and fall with river levels, the treatment approach of the moving boundaries problem (flooding and drying fronts) was based on the work by Zhao et al. [35] and Sleigh et al. [36].

\subsubsection{Model Validation}

Natural channel roughness decreases as water depth increases, i.e., as the water depth increases, the roughness affected by water depth becomes less. To meet the demand for the navigation between the TGD and GZD and ensure the safety of mooring along the channel, the allowable water level of the Gezhouba reservoir is from 63.0 to $66.5 \mathrm{~m}$, the corresponding water depth exceeds $15 \mathrm{~m}$, thus, river roughness is less affected by water level. The average comprehensive roughness of the reach between the TGD and ZGD ranges from 0.028 to 0.033 , the roughness coefficient is approximately 0.03 , according to previous engineering experience in this study. Moreover, mesh resolution combined with the water depths and selected time steps govern the Courant numbers in a model setup. The maximum Courant number was set to 0.5 , in the following simulation.

First, a one-dimensional (1D) hydrodynamic model of the TGD and GZD was established based on model parameter design, and the water level fluctuation process at the lower lock head of the ship lift was comparable to the prototype observation data. The water level fluctuation process at the multi-approach channels simulated by the two-dimensional (2D) numerical model was compared with the physical model test results from the Nanjing Hydraulic Research Institute, China. To this end, two metrics, $\mathrm{R}^{2}$ and Nash-Sutcliffe efficiency coefficient (NSE), were selected as the assessment 
indicators to identify the accuracy performance of the model adopted in this study. The $\mathrm{R}^{2}$ and NSE [37] can be expressed by Equations (6) and (7), respectively.

$$
\begin{gathered}
R^{2}=\frac{\left[\sum_{i=1}^{n}\left(H_{m, i}-\overline{H_{m}}\right)\left(H_{s, i}-\overline{H_{s}}\right)\right]^{2}}{\sum_{i=1}^{n}\left(H_{m, i}-\overline{H_{m}}\right)^{2} \sum_{i=1}^{n}\left(H_{s, i}-\overline{H_{s}}\right)^{2}} \\
N S E=1-\frac{\sum_{i=1}^{n}\left(H_{m, i}-H_{s, i}\right)^{2}}{\sum_{i=1}^{n}\left(H_{m, i}-\overline{H_{m}}\right)^{2}}
\end{gathered}
$$

where $H_{m, i}$ is the ith measured data and $H_{s, i}$ is the ith simulated data; the subscript " $m$ " denotes the measured data, whereas the subscript "s" represents the simulated data; $\overline{H_{m}}$ and $\overline{H_{s}}$ is the mean of observed data and simulated data, respectively; $n$ is the length of observations.

\section{D Mathematical Model}

The flow boundary conditions of the GHS and TGHS were plotted, as shown in Figure 5a, using the prototype hydrological data, and the accuracy of the 1D model was compared and validated with the observed water level at the lower lock head of the ship lift, as shown in Figure 5b. The results indicate that the water level variation process at the lower lock head of the ship lift simulated by the one-dimensional model was in good agreement with the overall trend of the prototype observation data $\left(R^{2}=0.961, \mathrm{NSE}=0.946\right)$, which more accurately reflected the water level process at the lower lock head of the ship lift. The calculation precision of this model reached as high as $10^{-4}$, therefore, the 1D model could exactly simulate the water level fluctuation of the approach channel under unsteady flow conditions between the TGD and GZD, and could provide a solid foundation for the 2D model investigation to determine the water level boundary at the Xitan Station.

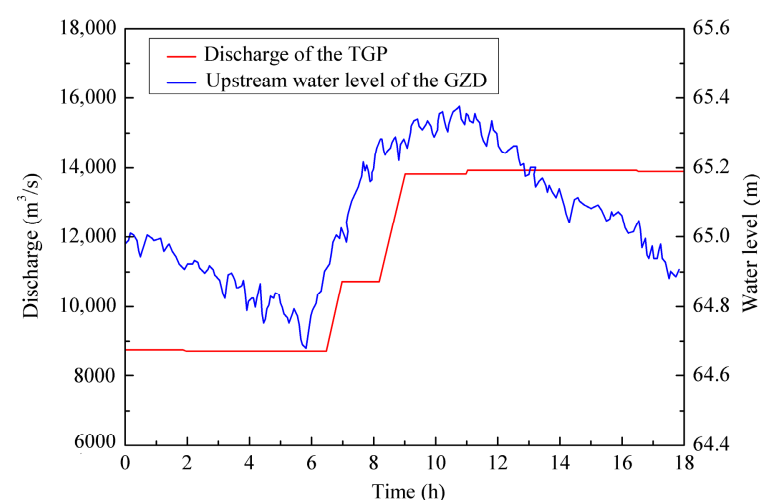

(a)

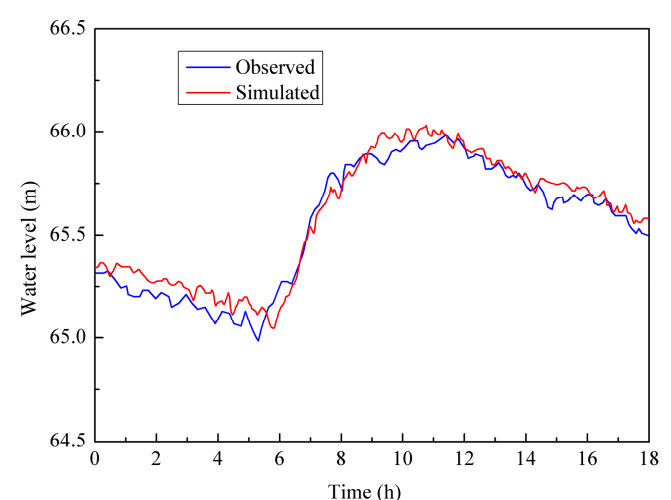

(b)

Figure 5. Boundary conditions and simulation results using a one-dimensional model. (a) Boundary conditions; (b) Comparison of the observed and simulated water level at the lower lock head of the ship lift.

\section{D Mathematical Model}

Considering the measured water level at the Xitan Station and the lower lock head of the ship lift from the physics model, a case was selected for numerical validation based on a two-dimensional shallow water model, i.e., the base flow of $10,000 \mathrm{~m}^{3} / \mathrm{s}$ is set, and the flow of the TGHS increases $2000 \mathrm{~m}^{3} / \mathrm{s}$ uniformly within $5 \mathrm{~min}$. Figure 6 a presents the discharge flow process at the TGHS and the water level process at the Xitan Station. As shown in Figure $6 b, c$, good consistency $\left(R^{2}=0.914\right.$, 
NSE $=0.833$ ) is observed between model calculation results and actual observation data at the lower lock head of the ship lift, as well as the simulated water level at the approach channel entrance is in accordance with the experimental measurements $\left(R^{2}=0.960\right.$, NSE $\left.=0.904\right)$. The calculation precision of this model can reach as high as $10^{-5}$, therefore, the mathematical model established, in this study, could precisely describe the water level fluctuation process at the approach channel entrance and the lower lock head of the ship lift. This provided a solid foundation for further analysis of unsteady flow for the multi-approach channels.

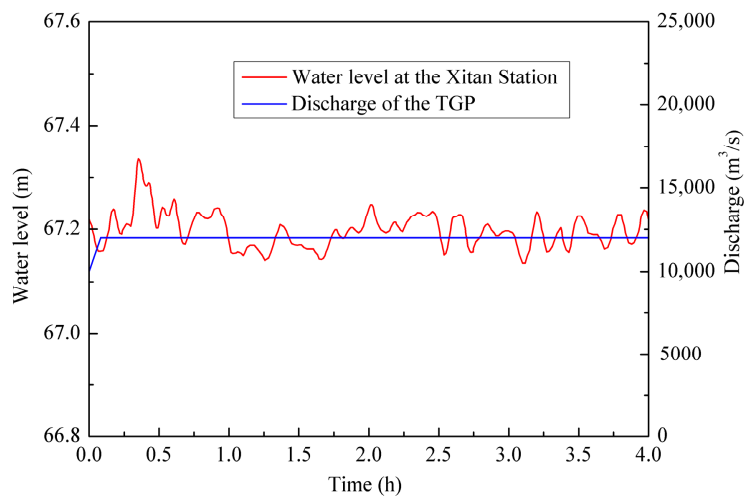

(a)

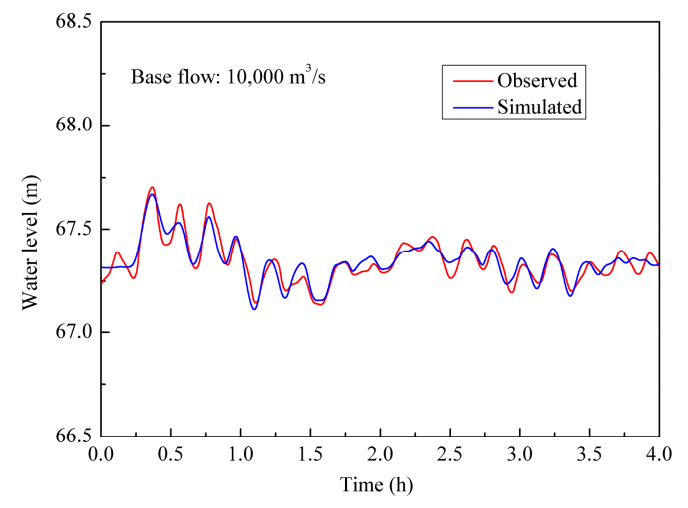

(b)

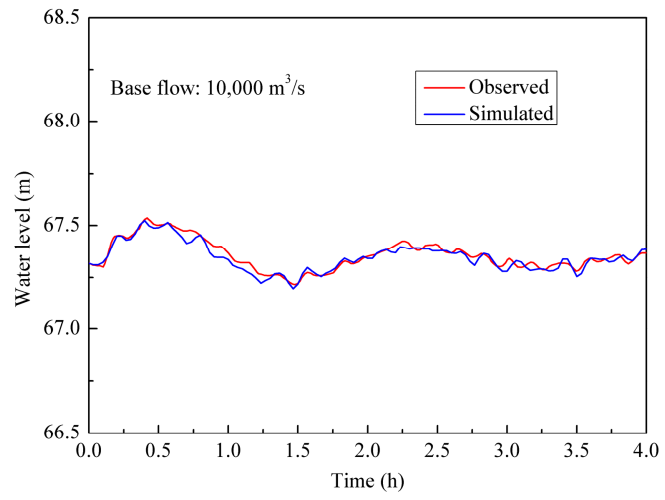

(c)

Figure 6. Boundary conditions and the simulated versus the measured water surface elevation. (a) Boundary conditions; (b) Water level at the lower lock head of the ship lift; (c) Water level at the entrance of the approach channel.

For the long river reach between the TGD and GZD, it was feasible to adopt a 1D model and a 2D model to analyze the water level fluctuations in the multi-approach channels. The one-dimensional model was used to obtain the water level for each section suitable for a long-distance waterway, with less time cost and adequate resolution, whereas the established 2D model presented the water level fluctuations and also facilitated the hydrodynamic analysis for different locations of hydropower stations and the presentation of wave propagation process as well as flow distribution. The prototype observation data of the water level at the lower lock head of the ship lift was utilized to calibrate the 1D model, and the physics model experimental data of water level was used to calibrate the 2D model. Good consistency was observed via the indicators $\left(R^{2}\right.$ and NSE) between the simulated results and the measured data, which indicated that the established hydrodynamic models could precisely describe the unsteady-flow process in the multi-approach channels. 


\section{Results}

\subsection{Water Level Fluctuation under the Complex Multivariate}

The excessive water level fluctuation at the lower lock head of the ship lift reduces the operating efficiency of the ship lift, and also adversely affects safe navigation of ships, docking, and depth control of the ship lift chamber; however, the excessive water level fluctuation at the entrance of the approach channel can cause ships to sway without constraints, or even result in ships bottoming out, threatening the safety of ships entering multi-approach channels. Therefore, considering the unsteady flow of the downstream approach channel of the TGP related to the complex variables such as initial water surface elevation, base flow, flow amplitude, regulation time of hydropower station, and locations of units, in this paper, we aim to investigate the influence of these factors on water level fluctuation in multi-approach channel and to determine the adverse case as a reference for navigation management. It is noteworthy that the hydropower station is set as a flow boundary and the water level boundary at the Xitan Station is obtained using a one-dimensional model.

\subsubsection{Initial Water Surface Elevation}

In this section, the base flow of the hydropower station is set to $5000 \mathrm{~m}^{3} / \mathrm{s}$, with a uniform increase of $2000 \mathrm{~m}^{3} / \mathrm{s}$ within $15 \mathrm{~min}$. Assuming that the Gezhouba reservoir water levels are 63.2, 64.6, and $66.2 \mathrm{~m}$, the corresponding water levels of the common approach channels are 63.23, 64.63, and $66.23 \mathrm{~m}$, respectively. The water level fluctuations at the common approach channel entrance and the lower lock head of the ship lift are investigated. It should be noted that the water level process is basically identical at the entrances of the planned lock approach channel and the existing approach channel, thus, the water level fluctuation at the existing approach channel entrance is considered to be an analyzed object. Water level fluctuations at the lower lock head of the ship lift and the existing approach channel entrance (as marked on Figures $1 \mathrm{~b}$ and 4 , hereinafter) computed from the numerical model results are shown in Figure 7.

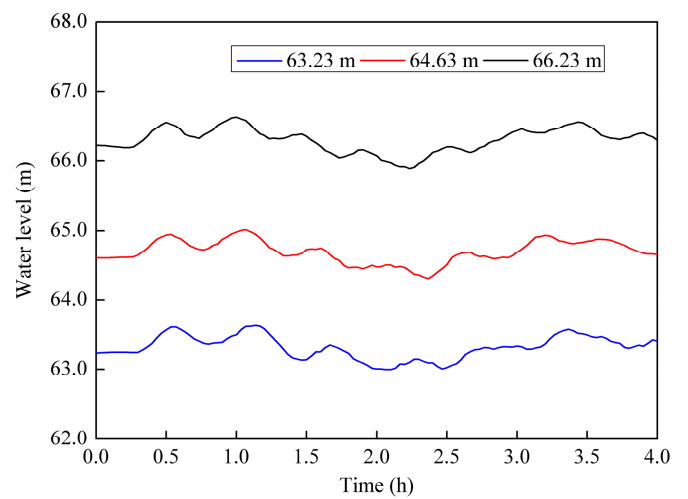

(a)

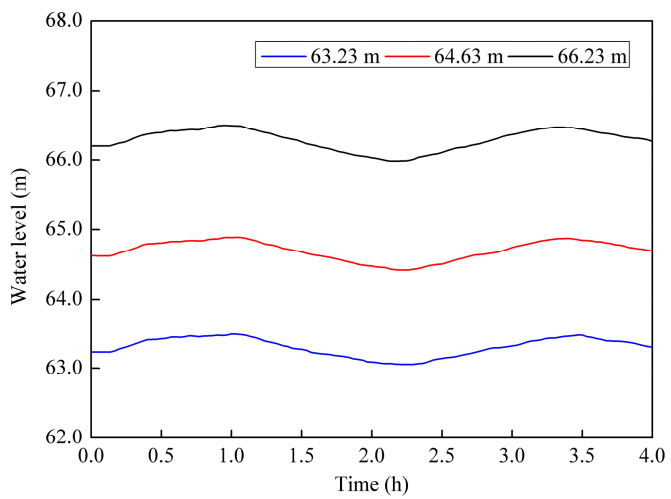

(b)

Figure 7. Water level variation process with initial water surface elevation. (a) Lower lock head of the ship lift; (b) Approach channel entrance.

Under a flow condition of $5000 \mathrm{~m}^{3} / \mathrm{s}$ base flow from the hydropower station, the fluctuating reflection and superimposition among the three "blind ends", including the lower lock head of the ship lift, the existing locks head, and the planned locks head, result in the inertial rising and falling with the form of the gravity longwave in the multi-approach channels which are regarded as an approximate sine curve with an initial water level as the balance axis. Wave amplitude at the lower lock head of the ship lift under different initial water surface elevations is relatively large, particularly the lower water surface elevation. For instance, when the initial water levels are 63.23, 64.63, and 66.23 m, the maximum wave amplitudes at the lower lock head of the ship lift are $0.37,0.34$, and $0.33 \mathrm{~m}$, 
respectively. In general, as the initial water level rises, the maximum wave amplitude at the lower lock head of the ship lift decreases gradually, but the impact is not significant.

\subsubsection{Base Flow}

The base flow of hydropower stations affects the water level fluctuation at the multi-approach channels. The base flow of the THGS are set to 5000, 15,000, and 25,000 $\mathrm{m}^{3} / \mathrm{s}$, respectively, with a uniform increase of $2000 \mathrm{~m}^{3} / \mathrm{s}$ within $15 \mathrm{~min}$ for different scenarios. The initial water surface elevation in the common approach channel under steady flow is $65.0 \mathrm{~m}$ via altering the water level at Xitan Station under the base flow conditions. The water level processes at the approach channel entrance and the lower lock head of the ship lift are presented in Figure 8.

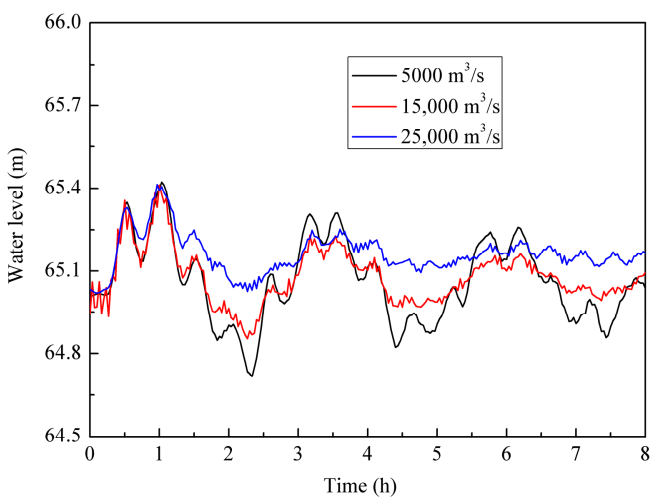

(a)

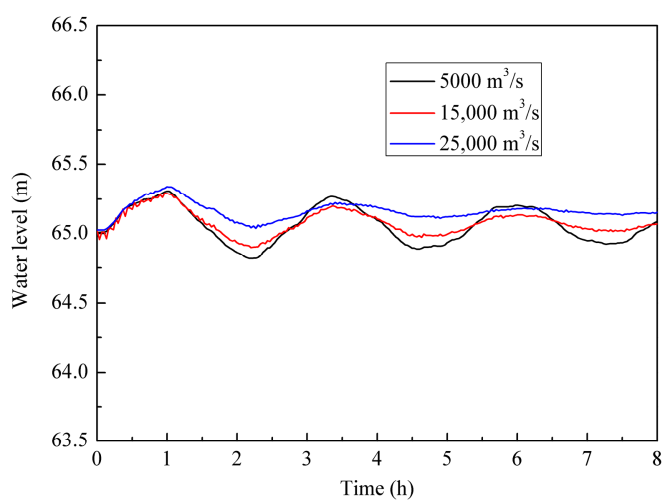

(b)

Figure 8. Water level variation process with the base flow. (a) Lower lock head of the ship lift; (b) Approach channel entrance.

There is a significant discrepancy between the water level fluctuation process at the approach channel entrance and the lower lock head of the ship lift, as shown in Figure 8. Unsteady flow in the approach channel presents the attenuation characteristics of gravity longwave, the fluctuation attenuation rates at the lower lock head of the ship lift and the approach channel entrance are faster with an increase in base flow; the slower the river base flow, the greater the wave amplitude at the lower lock head of the ship lift. The result indicates that when the base flow of the hydropower station reaches the minimum flow of $5000 \mathrm{~m}^{3} / \mathrm{s}$, the wave amplitude is unfavorable for the safe operation of the ship lift.

\subsubsection{Flow Amplitude}

Considering the water level fluctuation at the lower lock head of the ship lift and the entrance of the multi-approach channel, we focus on an unfavorable scenario when a smaller base flow manifests during the operation of the hydropower station. Therefore, the minimum allowable base flow is regarded to be $5000 \mathrm{~m}^{3} / \mathrm{s}$ in the downstream of TGHS, and can even increase to 1000, 2000, 3000, 4000, 5000 , and $6000 \mathrm{~m}^{3} / \mathrm{s}$ for flow amplitude within $15 \mathrm{~min}$, respectively. The water level fluctuation at the lower lock head of the ship lift and the approach channel entrance are investigated in this section. Moreover, a constant water level of $63.0 \mathrm{~m}$ at Gezhouba in the model is supposed to be unfavorable for navigation, and the downstream boundary in the 2D model is obtained through a one-dimensional hydrodynamic model. The water level calculation results at the lower lock head of the ship lift and the approach channel entrance are shown in Figure 9 when the hydropower station begins to increase the load within $15 \mathrm{~min}$. 


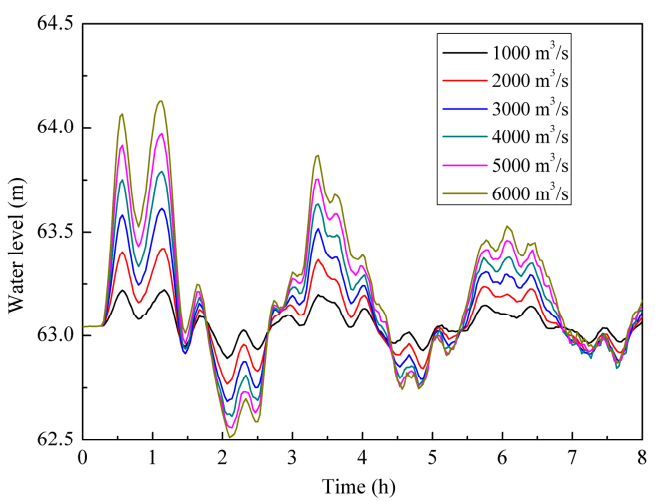

(a)

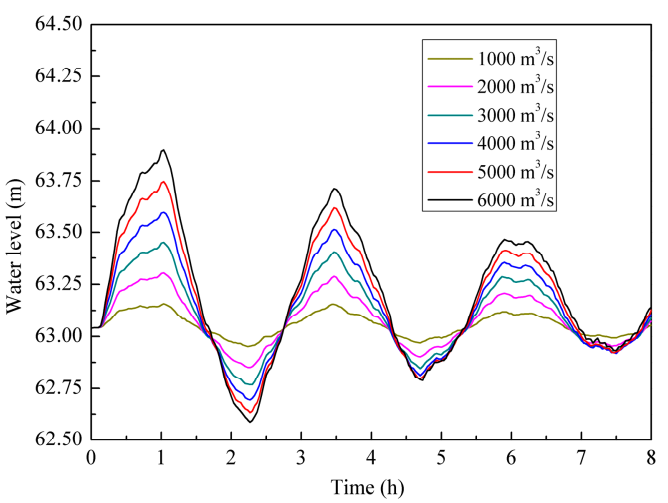

(b)

Figure 9. Water level variation process with flow variation amplitude. (a) Lower lock head of the ship lift; (b) Approach channel entrance.

The results indicate that the water level fluctuation in the approach channel is significantly affected by flow variation amplitude. The fluctuation amplitude at the multi-approach channels and the lower lock head of the ship lift under different flow levels is rather larger as compared with other hydraulic factors, and the fluctuation amplitude increases, as well as oscillating wave flow is more significant, with the increment of flow amplitude.

To characterize the water level fluctuations in the multi-approach channels under various flow variation amplitudes, considering the water level fluctuation at the multi-approach channels and the lower lock head of the ship lift during the initial period, the maximum water level rising and decreasing are introduced as a quantitative indicator to identify the variation range of water level. As presented in Table 1, the maximum water level fluctuation amplitude at the lower lock head of the ship lift increases with the growth of flow amplitude, and a maximum water level rising amplitude is around $0.17 \mathrm{~m}$ per $1000 \mathrm{~m}^{3} / \mathrm{s}$ amplitude. Likewise, the maximum water level fluctuation amplitude at the entrance of the existing and the planned approach channels increases with the increment of flow amplitude, the maximum water level rising amplitude is around $0.15 \mathrm{~m}$ for every additional $1000 \mathrm{~m}^{3} / \mathrm{s}$. In addition, with an increase in flow amplitude, the rising water level is sensitive to change in the amplitude as compared with the water level decreasing amplitude, and the rising value is larger than the latter.

Table 1. List of the maximum water level amplitudes (unit, $\mathrm{m}$ ).

\begin{tabular}{ccccccc}
\hline $\begin{array}{c}\text { Flow } \\
\text { Amplitude } \\
\left(\mathbf{m}^{3} / \mathbf{s}\right)\end{array}$ & \multicolumn{2}{c}{$\begin{array}{c}\text { Existing Approach } \\
\text { Channel Entrance }\end{array}$} & + & $\begin{array}{c}\text { The Planned Approach } \\
\text { Channel Entrance }\end{array}$ & $\begin{array}{c}\text { Lower Lock Head of the } \\
\text { Ship Lift }\end{array}$ \\
\cline { 2 - 7 } & + & - & + & - & + & - \\
\hline 1000 & 0.11 & -0.10 & 0.12 & -0.09 & 0.17 & -0.16 \\
\hline 2000 & 0.25 & -0.21 & 0.27 & -0.19 & 0.35 & -0.28 \\
\hline 3000 & 0.38 & -0.30 & 0.42 & -0.28 & 0.52 & -0.37 \\
\hline 4000 & 0.52 & -0.38 & 0.57 & -0.35 & 0.69 & -0.45 \\
\hline 5000 & 0.66 & -0.45 & 0.72 & -0.42 & 0.85 & -0.50 \\
\hline 6000 & 0.80 & -0.51 & 0.87 & -0.46 & 1.00 & -0.55 \\
\hline
\end{tabular}

Note: "+" denotes maximum water level rising, whereas "-" denotes maximum water level decreasing.

Figure 9 shows the water level process at the lower lock head of the ship lift and the entrance of the multi-approach channel. Due to wave reflections among the three "blind ends", including the existing lock heads, the lower lock head of the ship lift, and the planned lock heads, as well as the inertial fluctuation of the water body, the water level fluctuation process at the lower lock head of the 
ship lift is regarded to be the superposition of river longwave and oscillating wave, and the fluctuation situation is rather complicated. Significant water level fluctuation at the multi-approach channels may cause unsafe navigation conditions. As presented in Table 1, with a base flow of $5000 \mathrm{~m}^{3} / \mathrm{s}$ and $15 \mathrm{~min}$ unit regulation, when the flow amplitude exceeds $3000 \mathrm{~m}^{3} / \mathrm{s}$, the water level fluctuation at the lower lock head of the ship lift exceeds the navigation threshold value of $0.5 \mathrm{~m} \mathrm{[38].} \mathrm{Therefore,} \mathrm{it} \mathrm{is}$ recommended that the regulation of a hydropower station should control the flow amplitude within the range of $3000 \mathrm{~m}^{3} / \mathrm{s}$.

\subsubsection{Flow Regulation Time}

Powerhouse startups and shutdowns are the most critical flow parameters for evaluating navigation impacts [24]. According to the actual operating data of the TGHS, the flow regulation time of a single unit under a normal operating condition is $15 \mathrm{~min}$, whereas a single unit under an abnormal operating condition is $5 \mathrm{~min}$. Flow regulating time or unit flow variability exerts an influence on the water level fluctuations at the multi-approach channels and the lower lock head of the ship lift.

To investigate the water level fluctuations at the multi-approach channels and the lower lock head of the ship lift under various flow regulation times, in this section, the base flow of the hydropower station is set to $15,000 \mathrm{~m}^{3} / \mathrm{s}$, the flow regulation time is set to increase $2000 \mathrm{~m}^{3} / \mathrm{s}$ uniformly within 5 , 15 , and $30 \mathrm{~min}$, and the corresponding flow variabilities are $6.67,2.22$, and $1.11 \mathrm{~m}^{3} / \mathrm{s}^{2}$, respectively. Figure 10 presents the computed water level process at the approach channel entrance and the lower lock head of the ship lift under the same flow amplitude.

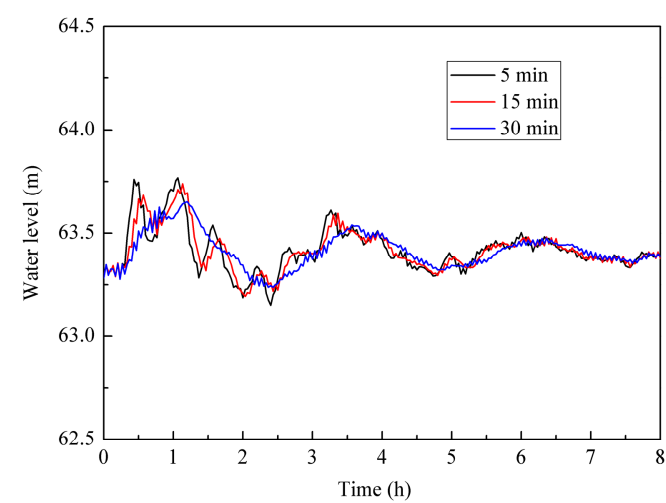

(a)

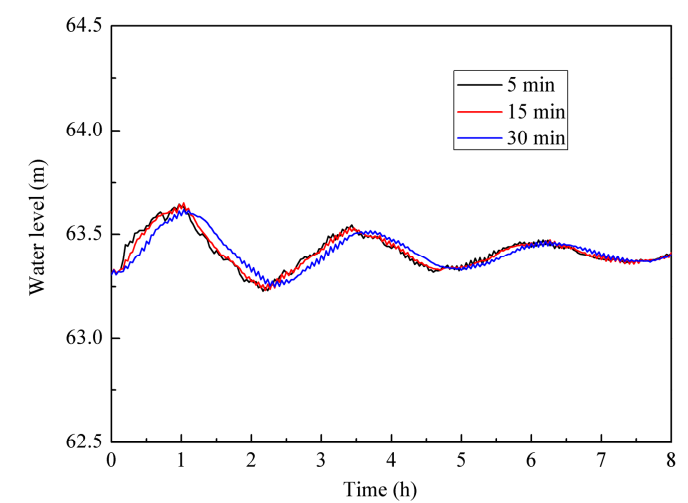

(b)

Figure 10. Water level variation process with regulation time. (a) Lower lock head of the ship lift; (b) Approach channel entrance.

As shown in Figure 10, the wave amplitude at the lower lock head of the ship lift and the approach channel entrance under different flow regulation times are distinct from each other, but the subsequent waveforms are consistent, and the amplitude decreases gradually with the wave energy attenuation of gravity longwave. In this section, with the assumption of flow regulation times of 5, 15, and $30 \mathrm{~min}$, the maximum amplitudes corresponding to the water level at the lower lock head of the ship lift are $0.48,0.39$, and $0.34 \mathrm{~m}$, respectively, whereas corresponding maximum amplitudes at the approach channel entrances are $0.35,0.34$, and $0.29 \mathrm{~m}$, respectively. In summary, owing to the reflection and narrowing effect at the closed end of the lower lock head of the ship lift, the shorter the flow adjustment time, the greater the flow variability manifested, and the greater the wave amplitude will be at the approach channel entrance and the lower lock head of the ship lift. Moreover, safe operation of the ship lift is greatly affected when the unit is in a state of sudden loading operation.

\subsubsection{Locations of Hydropower Station under Operation}

The Three Gorges Hydropower Station (TGHS) is the world's largest hydroelectric power plant in terms of installed capacity, the total installed power capacity is 22,500 MW from 34 stand-alone 
turbines $[39,40]$. The hydropower stations on the left and right banks of the TGP are arranged on both sides of the gated spillway, and there are underground power stations in the mountain on the right bank (Figure 1a). A natural river channel is downstream of the TGP instead of a straight one. Considering the asymmetrical arrangement of the hydropower station and the various operation combinations, the units in different locations participate in peak operation, which may lead to large differences in the period of water level fluctuation, wave height, and wave height variability in the multi-approach channels. Therefore, to analyze the water level fluctuation pattern of the downstream approach channel and the lower lock head of the ship lift under the operation modes of various combinations for the left bank, right bank, and underground hydropower units, the calculated case is set to $5000 \mathrm{~m}^{3} / \mathrm{s}$ for the base flow of the TGHS, with a uniform increase of $2000 \mathrm{~m}^{3} / \mathrm{s}$ within $15 \mathrm{~min}$. To identify the various possible cases, underground hydropower stations, left bank hydropower stations, and right bank hydropower stations are recorded as A, B, and C, respectively. Assuming that a combination of the left bank, right bank, and underground hydropower stations may occur in operation, a total of seven scenarios are $A, B, C, A+B, A+C, B+C$, and $A+(B+C)$, respectively.

Considering different locations of hydropower stations in operation, the water level fluctuation process at the multi-approach channel entrance and the lower lock head of the ship lift is identical with every case regardless of various operation combinations for large-scale hydropower stations, as shown in Figure 11. Therefore, the water level fluctuation at the approach channel entrance and the lower lock head of the ship lift is slightly impacted by the combined operation modes for hydropower stations at different locations, which exerts a significant role in guidance for operational management and scenario design of large-scale hydropower stations in the future.

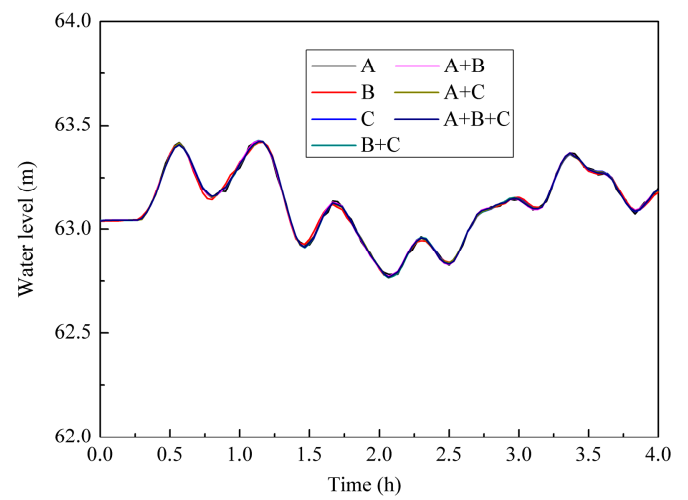

(a)

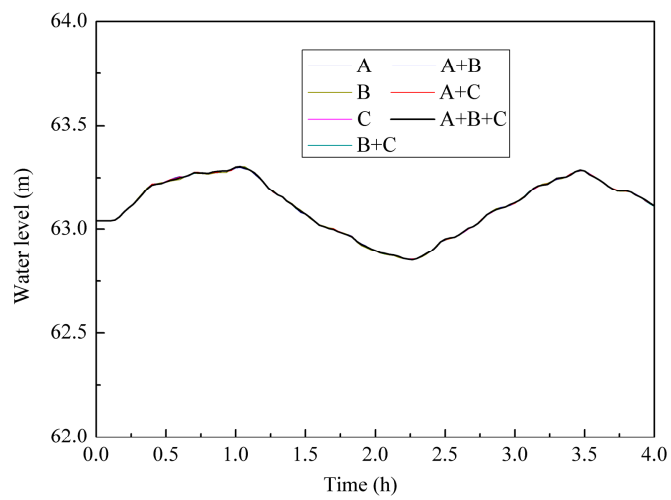

(b)

Figure 11. Water level variation process concerning locations of hydropower stations. (a) Lower lock head of the ship lift; (b) Approach channel entrance.

\subsection{Peak-Shaving Mode of Hydropower Station}

The GZD is located $38 \mathrm{~km}$ downstream of the TGD, and the Gezhouba reservoir with daily regulating capacity plays a counter-regulating role in the hydropower station regulation. In Section 3.1, water level fluctuation is investigated at the approach channel entrance and the lower lock head of the ship lift under the assumption of a constant water level at the GHS, however, the study period is short and the flow amplitude is a single trend change which does not reflect the actual water level process at the multi-approach channels. Therefore, considering the daily load regulation of the GHS, in this section, the typical single-peak and double-peak regulations occurring during the daily operation of the TGHS over the past ten years are selected as the case study.

Unsteady flow generated from the regulation of the cascade hydropower station significantly alters the navigation conditions of waterways located downstream of the TGD and also has a strong influence on the water level fluctuation in the multi-approach channels. The complicated wave propagation as a result of TGHS and GHS operation is sketched in Figure 12 and shows the following: (i) Provided that the cascade hydropower station is under load-increasing operation, the discharge flow of the 
TGHS and GHS increases abruptly, the downstream water level of the TGHS rises rapidly to develop a positive rising wave, whereas the upstream water level of the GHS rapidly decreases to develop a negative rising wave. (ii) When the cascade hydropower station is under load-reducing operation, the discharge flow of TGHS and GHS suddenly decreases, a positive falling wave in the downstream of TGHS is developed, while a negative rising wave in the upstream of GHS is developed. In short, there are three various operational modes of the cascade hydropower station, i.e., load-increasing operation, load-reducing operation, and constant load, these various combinations make unsteady flow in the multi-approach channels more complex, particularly the water level fluctuation.

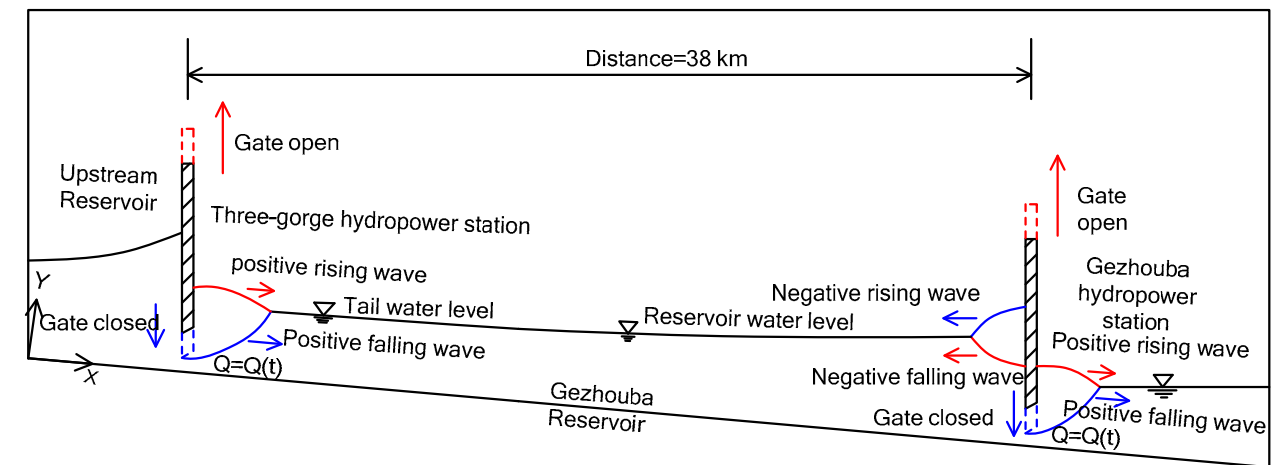

Figure 12. Schematic diagram of the Three Gorges and Gezhouba cascade hydropower station.

\subsubsection{Single-Peak Regulation}

The single-peak is a common phenomenon for TGHS operation, with the peak period of 9:00-21:00 and trough hours at other times over the entire day. The maximum period of hourly variation of the discharge flow (base flow $=5000 \mathrm{~m}^{3} / \mathrm{s}, \Delta \mathrm{Q}=2000 \mathrm{~m}^{3} / \mathrm{s}$, and $\Delta \mathrm{t}=30 \mathrm{~min}$ ) according to the TGHS operation in the past ten years was on 2 March 2015. The flow and water level boundaries during this period are presented in Figure 13.

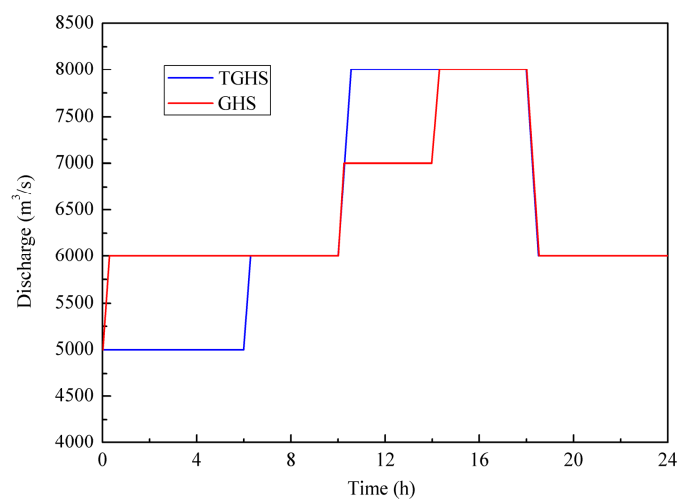

(a)

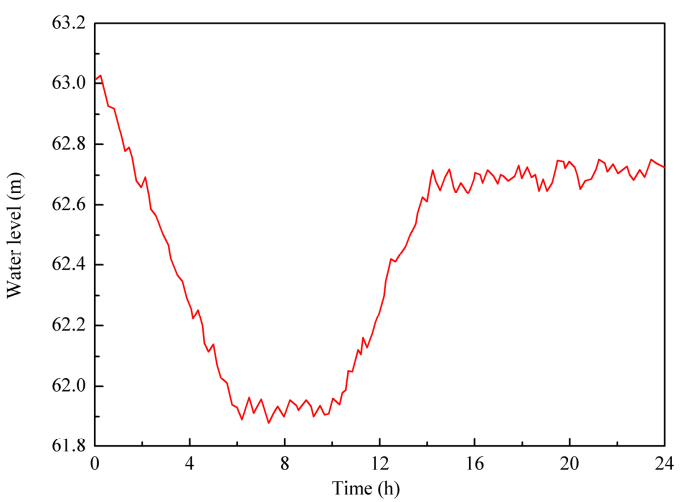

(b)

Figure 13. Computation boundary. (a) Flow process of the Three Gorges Hydropower Station (TGHS) and the Gezhouba Hydropower Station (GHS); (b) Water level at the Xitan Station.

Quantitative Analysis

As shown in Figure 14, the TGHS increases gradually from 5000 to $8000 \mathrm{~m}^{3} / \mathrm{s}$ under load-increasing operation, flow amplitude is regarded as $3000 \mathrm{~m}^{3} / \mathrm{s}$, a maximum hourly variation of the water level at the lower lock head of the ship lift is $0.40 \mathrm{~m} / \mathrm{h}$, and water levels at the existing approach channel and the planned approach channel are 0.29 and $0.30 \mathrm{~m} / \mathrm{h}$, respectively. It indicates that the process of water level fluctuation can meet the requirements of safe operation of the ship lift, and maximum hourly fluctuation of water level appears frequently at the period of maximum flow amplitude. 


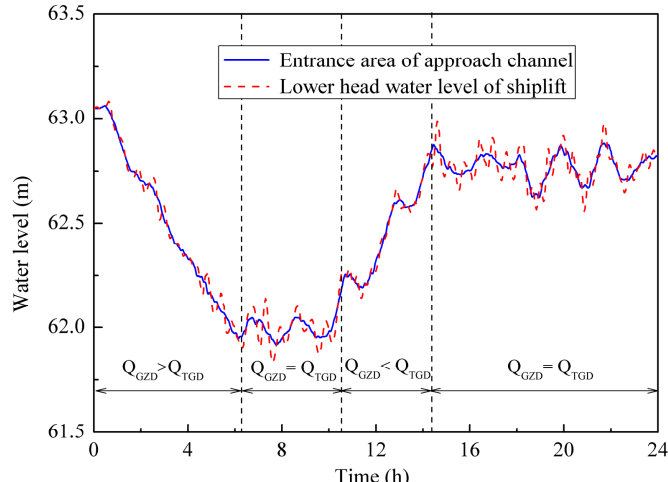

(a)

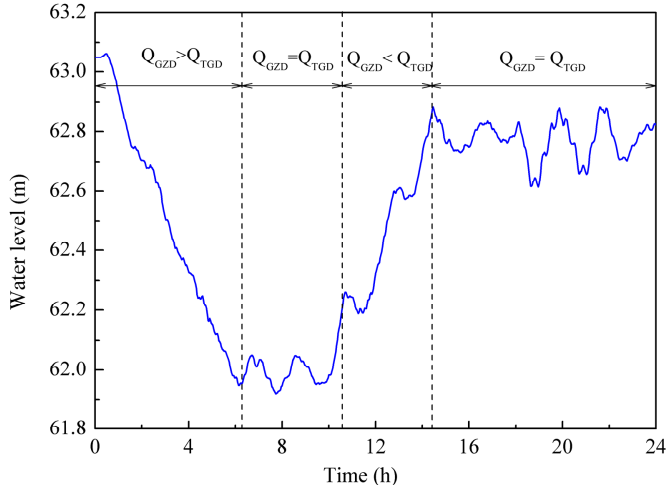

(b)

Figure 14. Water level variation process regarding single-peak regulation. (a) Approach channel entrance and lower lock head of the ship lift; (b) The planned approach channel entrance.

\section{Qualitative Analysis}

Water level fluctuation in a multi-approach channel is a longwave motion induced by flow amplitude and net flow between the TGHS and GHS, and the process of water level fluctuation at the lower lock head of the ship lift is manifested as a process of inertial rise or drop, as well as hydraulic superposition. To be specific, when the discharge flow $\mathrm{Q}_{\mathrm{TGHS}}$ of TGHS is less than $\mathrm{Q}_{\mathrm{GHS}}$ of GHS, the water level fluctuation in the multi-approach channels is a continuous negative falling process with the action of gravity longwave; while the discharge flow $\mathrm{Q}_{\mathrm{TGHS}}$ of TGHS is greater than $\mathrm{Q}_{\mathrm{GHS}}$ of GHS, the water level fluctuation in the multi-approach channels manifests as a continuous positive rising process with the action of gravity longwave; when the discharge flow $\mathrm{Q}_{\text {TGHS }}$ of TGHS is consistent with $\mathrm{Q}_{\mathrm{GHS}}$ of GHS, the water level fluctuations at the lower lock head of the ship lift and the multi-approach channels are composed of the rising wave or falling wave induced by the flow regulation of the cascade hydropower station, as well as flow amplitude in the multi-approach channels.

To visually present the reciprocating wave flow process in the multi-approach channels under the single-peak regulation, the typical wave propagation path at $t=6.33,6.70,6.73,6.77,6.97$, and $7.03 \mathrm{~h}$ in the multi-approach channels are selected for analysis, as is depicted in Figure 15.

The flow released from the hydropower station directs the current in the downstream river into the lower multi-approach channels. The water level rising or falling will lead to the reciprocating oscillation of water wave, thus, the water surface elevation increases and decreases periodically. For instance, the water moves from the approach channel entrance to the appendix pouring and slowly transports to the closed end, the rising water wave is reflected by the sidewalls, bends, forks, narrow beams, and closed ends, then, the reflected wave and the subsequent primary wave are superimposed so that the water surface manifests up and down repeatedly. From Figure 15, the reflection phenomenon appears at the planned lock approach channel, the existing lock approach channel, and the ship lift's approach channel, in sequence. In the process of the water level falling, the water wave in the multi-approach channels flows into the main channel, and the falling water wave goes in the opposite direction, the reflection phenomenon is present. Energy conversion and transfer occur in the adjacent water bodies with different velocities, forming secondary waves as a result of the fluctuation of the water surface. The process of water level fluctuations and reflections in the multi-approach channels also contributes to the formation, development, and disappearance of eddies at the common approach channel entrance. 

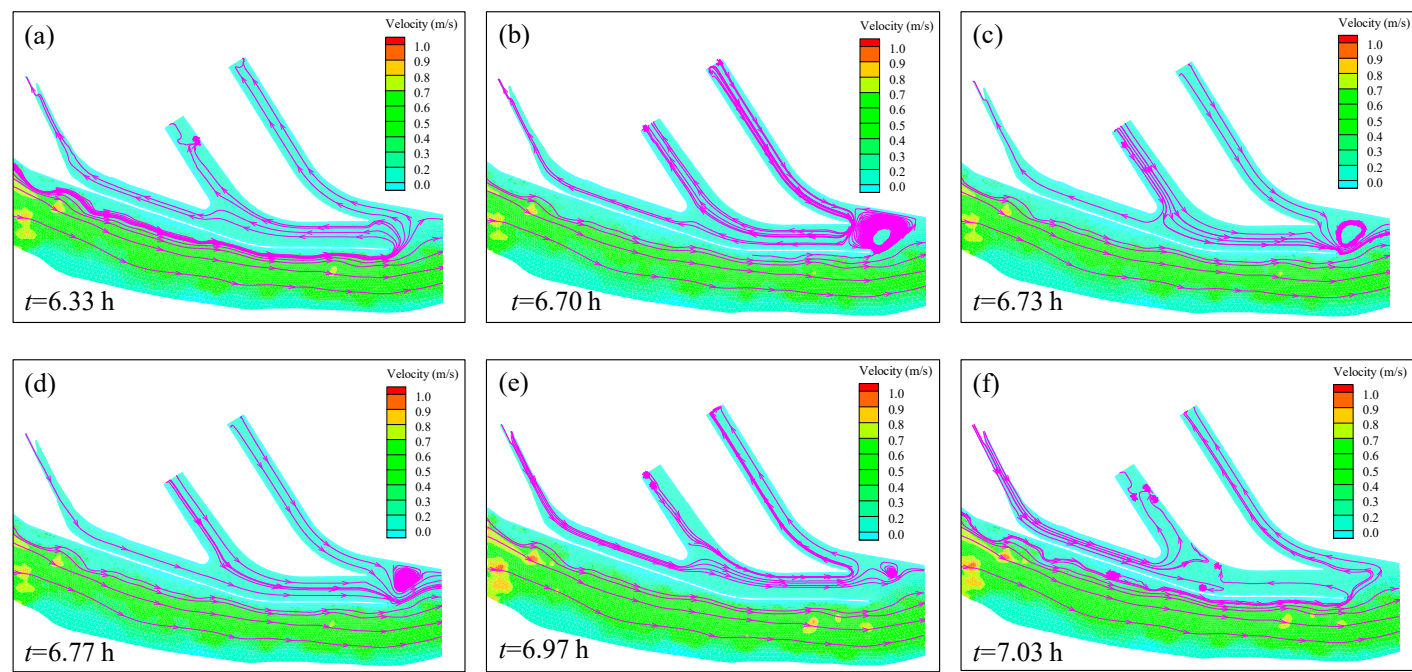

Figure 15. The typical streamline and velocity in multi-approach channels under single-peak regulation of hydropower stations. (a) $t=6.33 \mathrm{~h}$; (b) $t=6.70 \mathrm{~h}$; (c) $t=6.73 \mathrm{~h}$; (d) $t=6.77 \mathrm{~h}$; (e) $t=6.97 \mathrm{~h}$; (f) $t=7.03 \mathrm{~h}$.

\subsubsection{Double-Peak Regulation}

In the double-peak mode, 8:00-12:00 is the early peak period, and 18:00-22:00 is the late peak period. The period of the largest hourly variation of the discharge flow $\left(\Delta \mathrm{Q}=4000 \mathrm{~m}^{3} / \mathrm{s}\right)$ from the THGS is selected as the analysis period on 9 January 2016. The flow process of the TGHS on that day was a typical double-peak regulation. Boundary conditions of the flow regulation process of the TGHS and GHS are determined by flood data (Figure 16).

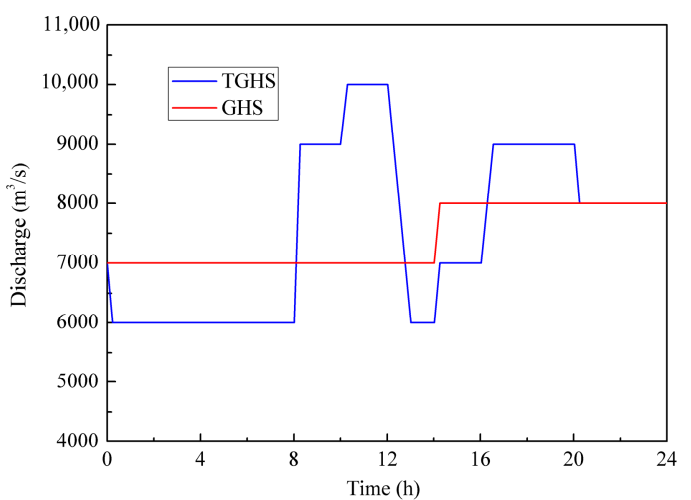

(a)

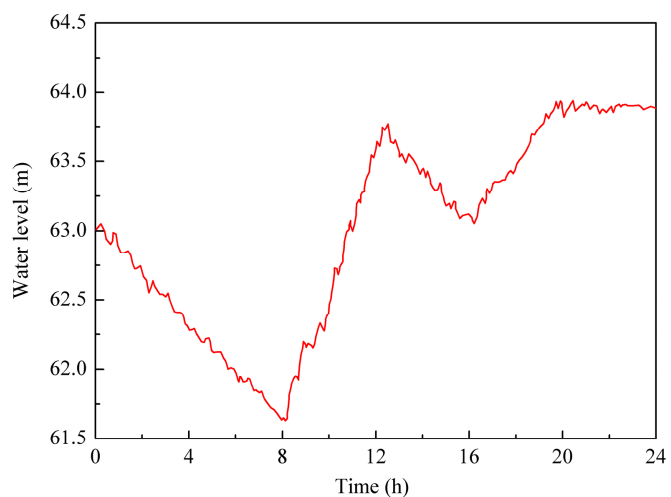

(b)

Figure 16. Boundary conditions. (a) Daily regulation between the TGHS and GHS; (b) Water level at the Xitan Station.

\section{Quantitative Analysis}

The typical water level changing process at the lower lock head of the ship lift and the entrance of the multi-approach channel is shown in Figure 17. 


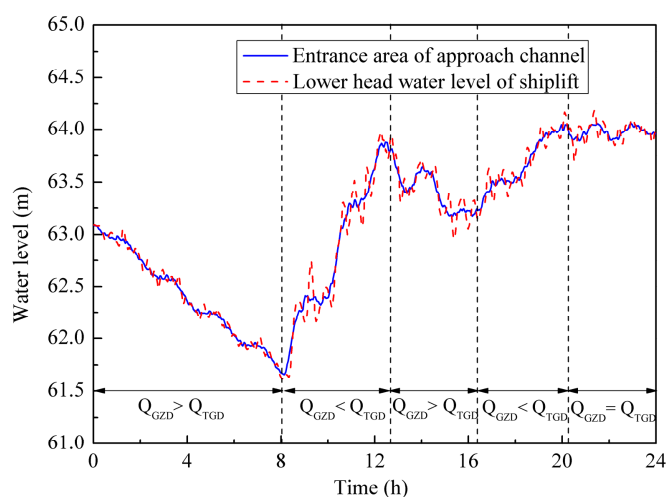

(a)

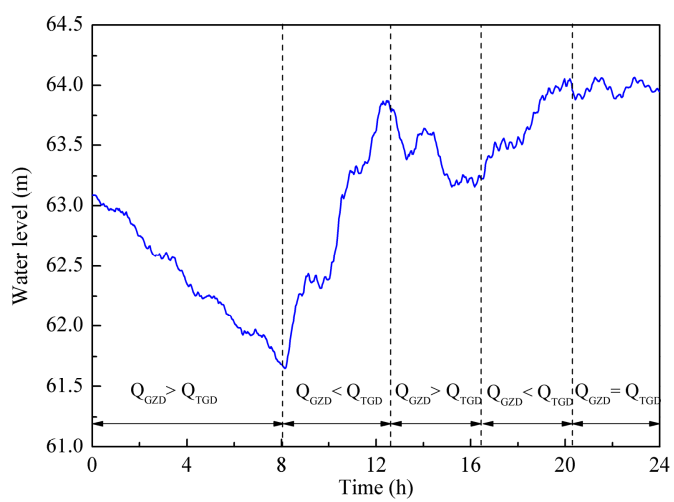

(b)

Figure 17. Water level variation process regarding double-peak regulation. (a) Approach channel entrance and lower lock head of the ship lift; (b) The planned approach channel entrance.

The initial discharge flow of the GHS is $7000 \mathrm{~m}^{3} / \mathrm{s}$, and it increases evenly by $1000 \mathrm{~m}^{3} / \mathrm{s}$ within $15 \mathrm{~min}$ at $14 \mathrm{~h}$, thus the load-increasing operation of the TGHS shows a double-peak feature, i.e., the maximum peak flow occurs between 8 and $10.3 \mathrm{~h}$. First, the flow increases evenly by $3000 \mathrm{~m}^{3} / \mathrm{s}$, staying stable for about $1.7 \mathrm{~h}$, then, increases evenly by $1000 \mathrm{~m}^{3} / \mathrm{s}$, and the final peak reaches $10,000 \mathrm{~m}^{3} / \mathrm{s}$. In this case, the maximum hourly variation of water level at the lower lock head of the ship lift is $0.98 \mathrm{~m} / \mathrm{h}$, and at the entrances of the existing approach channel and the planned approach channel the maximum hourly variation of water levels are $0.79 \mathrm{~m} / \mathrm{h}$ and $0.87 \mathrm{~m} / \mathrm{h}$, respectively, which exceeds the water level fluctuation threshold at the lower lock head of the ship lift and the approach channel entrance. Furthermore, the second peak occurs during the period 14.0-16.5 $\mathrm{h}$ when the flow increases by $3000 \mathrm{~m}^{3} / \mathrm{s}$, and finally the peaks reach $9000 \mathrm{~m}^{3} / \mathrm{s}$, the maximum hourly variation amplitude of water level at the lower lock head of the ship lift is $0.43 \mathrm{~m} / \mathrm{h}$ and at the entrances of the existing approach channel and the planned approach channel they are 0.26 and $0.32 \mathrm{~m} / \mathrm{h}$, respectively. The water level amplitude meets the safe operation requirements of the ship lift and the approach channel entrance.

Since the net flow $\left(\Delta \mathrm{Q}=1000 \mathrm{~m}^{3} / \mathrm{s}\right)$ between the TGHS and GHS is less than the net flow $\left(\Delta \mathrm{Q}=3000 \mathrm{~m}^{3} / \mathrm{s}\right)$, the maximum hourly variation of water level under the net flow of $3000 \mathrm{~m}^{3} / \mathrm{s}$ at the entrance of the approach channel and the lower lock head of the ship lift is less than that of the former. Therefore, the results show that net flow between the TGHS and GHS under the double-peak regulation of hydropower stations is an important factor influencing the maximum hourly variation of water level at the lower lock head of the ship lift and the multi-approach channels.

\section{Qualitative Analysis}

The water level fluctuations at the existing approach channel entrance and the lower lock head of the ship lift are recognized to be the action of shallow gravity longwave induced by the flow amplitude and net flow between the TGHS and GHS. When the Three Gorges discharge flow, $\mathrm{Q}_{\text {TGHS, }}$ is smaller than the GHS discharge flow, $\mathrm{Q}_{\mathrm{GHS}}$, a continuous negative water falling process is developed in the multi-approach channels; whereas the Three Gorges discharge flow, $\mathrm{Q}_{\mathrm{TGHS}}$, is greater than the GHS discharge flow, $Q_{\mathrm{GHS}}$, with a constant flow of 7000 or $8000 \mathrm{~m}^{3} / \mathrm{s}$ for the GHS, a continuous water rising process is developed during different periods.

As shown in Figure 18, the time at $t=8,12,16$, and $20 \mathrm{~h}$ are utilized to present the complicated wave flow phenomenon at the multi-approach channels, and the results show that the river gravity longwave is transmitted into the multi-approach channels via the entrance, inertial rising and falling influenced by the closed end or river bands are developed in the multi-approach channels, as evidenced by the superposition of river longwave and oscillating wave flow. This phenomenon indicates that wave fluctuations and reflections in the multi-approach channels are extremely complicated during the double-peak operation of the cascade hydropower station. 

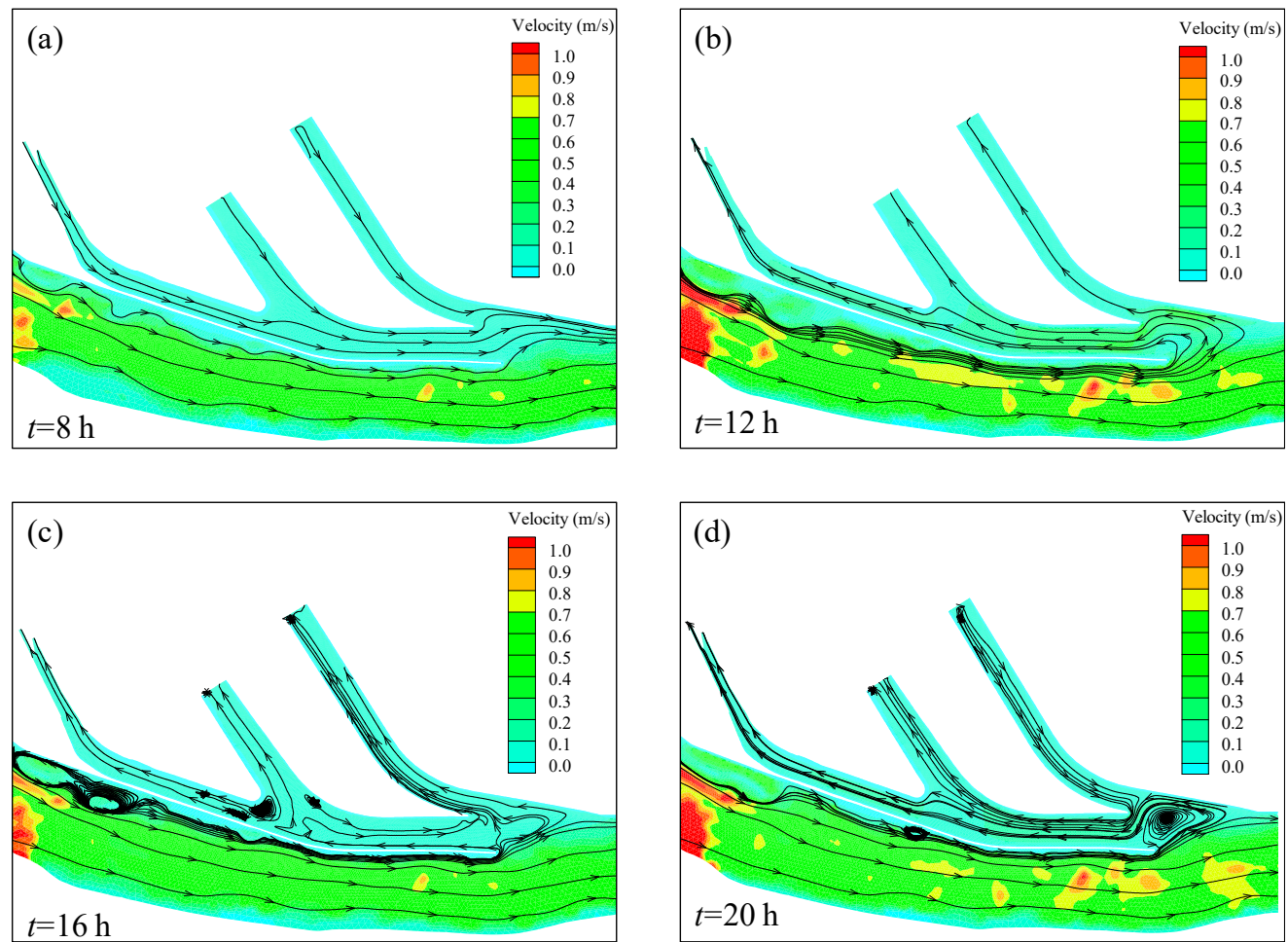

Figure 18. The typical streamline and velocity in multi-approach channels under double-peak regulation of hydropower stations. (a) $t=8 \mathrm{~h}$; (b) $t=12 \mathrm{~h}$; (c) $t=16 \mathrm{~h}$; (d) $t=20 \mathrm{~h}$.

\section{Discussion}

Numerous limitations remain in the unsteady flow generated from the application of hydropower station regulations regarding multi-approach channels and need further research as follows:

- Navigation conditions in the approach channel play an indispensable role in the water transportation industry, and the unsteady flow induced by hydropower stations in the approach channel is rather complex because of the different terrain boundaries. Prior studies have focused more on water level amplitude, velocity, hydraulic gradient, and other shipping hydro impact factors in a long waterway or single approach channel instead of multi-approach channels. Although navigation conditions are investigated in many cases according to engineering background, the water level fluctuations in the multi-approach channel fail to be revealed in the context of the broader scientific literature regarding unsteady flow induced by hydropower station. Moreover, navigation conditions change based on the lock approach configuration, thus common navigation standards (e.g., the maximum hour or daily amplitude of water level, transverse velocity, and longitudinal velocity) are hard to be determined in the navigation domain.

- Velocity and hydraulic gradient are important hydraulic factors for determining navigation conditions of a waterway or approach channel. In terms of an approach channel, the transverse and longitudinal velocities, in general, are regarded to be the diagnostic indicators for the navigation according to the guidelines $[5,6,38]$. However, constant velocity is inappropriate for the actual unsteady physics scenarios induced by hydropower stations. Thus, it is unreasonable for engineers and decision-makers to determine navigation conditions. Furthermore, navigation standards under unsteady flow also need to be investigated. In this study, from engineering experience, it is known that the velocity is relatively small after an existing approach channel entrance area is extended, thus, in this paper, we only investigate the water level fluctuation process. Furthermore, unsteady flow in multi-approach channels is an interactive process of water level 
and current; the hydraulic gradient and velocity variations of key points in the multi-approach channels are further analyzed in combination with a large-scale physical model test.

- The dispatching mode of a cascade hydropower station exerts a significant impact on navigation conditions in the multi-approach channels. Currently, few studies are able to exhibit the water level fluctuation process considering the operation of a counter-regulation hydropower station, particularly in multi-approach channels (the existing approach channel, the planned approach channel, and the approach channel of the ship lift). Prior studies have focused more on navigation in long waterways instead of in multi-approach channels. In addition, there are several limitations. In the study, single-peak and double-peak regulation operations are merely considered, regardless of the peak regulation over the entire year, and reducing-load operation or even emergency shutdowns of hydropower units under abnormal operating conditions needs further study.

- Hydropower station operation undertakes the function of peak regulation and power generation efficiency and also needs to meet the requirements of navigation conditions of multi-approach channels. Additionally, considering the importance of renewable energy sources development in achieving sustainability goals, more importance should be attached to the conservation of the environmental health of a river. Thus, it is essential to comprehensively consider the connection between the peaking and the navigational flow conditions in terms of the navigation capacity of multi-approach channels, and further research should be undertaken to investigate multi-objective optimization scheduling regarding hydropower station operation, navigational hydraulic factors, and environmental flows.

- In situ tests, physics model tests, and numerical techniques are utilized to obtain accurate navigation conditions such as water level fluctuations and flow field in multi-approach channels. Notably, the smaller scale physics model may have led to unauthentic results, these kinds of limitations may have been derived from cost control and other uncontrollable factors. In addition, a higher resolution numerical model needs to be developed in the future.

\section{Conclusions}

Unsteady flow induced by hydropower stations exerts a significant impact on navigation conditions in multi-approach channels. In this study, 1D and 2D hydrodynamic models are established based on the geomorphological features and topographic data between the TGD and GZD. Water level fluctuations at the entrance of multi-approach channels and the lower lock head of a ship lift are revealed; subsequently, considering the regulation mode of a cascade hydropower station, the water level fluctuations are analyzed, and the water level oscillation process in the multiple approach channels are investigated. The following conclusions can be drawn:

- With a rise of initial water surface elevation, the maximum amplitude at the lower lock head of the ship lift decreases gradually; with the increment of base flow, wave attenuation at the lower lock head of the ship lift and the approach channel entrance is faster. The maximum wave amplitude at the multi-approach channel entrance and the lower lock head of the ship lift increases with an increase in flow amplitude. The shorter the flow regulation time, the greater the wave amplitude will be at the lower lock head of the ship lift and the approach channel entrance; and the fluctuation process of water level is unaffected when units at different positions are involved in the peak regulation. In general, one of the more significant findings to emerge from this study is that flow amplitude is the most significant factor influencing water level fluctuation at the multi-approach channels and the lower lock head of a ship lift.

- The water level in the multi-approach channels fluctuates greatly under the most adverse conditions including lower initial water surface elevation, smaller base flow, larger flow variation, and shorter regulation time of the hydropower station. Moreover, the most unfavorable conditions for water level fluctuation are when the base flow is $5000 \mathrm{~m}^{3} / \mathrm{s}$. When the flow regulation is set to 
$5 \mathrm{~min}$ and flow amplitude reaches $3000 \mathrm{~m}^{3} / \mathrm{s}$, the wave amplitude at the lower lock head of the ship lift exceeds the threshold value $0.5 \mathrm{~m} / \mathrm{h}$ at the constant water level of the GZD.

- Considering the regulation mode of the cascade hydropower station, water level fluctuation in the multi-approach channels is primarily induced by flow amplitude and the net flow between the TGHS and GHS, and the water level fluctuation process at the lower lock head of the ship lift is manifested as inertia rising or falling as a result of the superposition of river water level fluctuation and the reciprocal wave flow in the multi-approach channels.

Author Contributions: Conceptualization, Z.W. and X.W.; methodology, Z.W. and J.A.; software, Z.W., J.A., and B.D.; validation, Z.W.; formal analysis, Z.W.; investigation, Z.W.; resources, Y.L. (Yun Li), X.W., and J.A.; data curation, Z.W.; writing-original draft preparation, Z.W.; writing-review and editing, Z.W., Y.L. (Yun Li), X.W., B.D., and Y.L. (Yipeng Liao); visualization, Z.W.; supervision, Y.L. (Yun Li) and X.W.; project administration, Y.L. (Yun Li); funding acquisition, Y.L. (Yun Li) and X.W. All authors have read and agreed to the published version of the manuscript.

Funding: This research was jointly funded by the Three Gorges Follow-up Work Research Project (SXXTD-2018-8) and National Key Research and Development Program of China (2016YFC0401906).

Conflicts of Interest: The authors declare no conflict of interest.

\section{References}

1. Martinelli, D.; Schonfeld, P. Approximating delays at interdependent locks. J. Waterw. Port Coast. Ocean Eng. 1995, 121, 300-307. [CrossRef]

2. Mihic, S.; Golusin, M.; Mihajlovic, M. Policy and promotion of sustainable inland waterway transport in Europe-Danube River. Renew. Sustain. Energy Rev. 2011, 15, 1801-1809. [CrossRef]

3. Liao, P. Improved analytical model for estimating the capacity of a waterway lock. J. Waterw. Port Coast. Ocean Eng. 2018, 144, 04018021. [CrossRef]

4. Huang, J.; Nieh, C.; Kuo, H. Risk assessment of ships maneuvering in an approaching channel based on AIS data. Ocean Eng. 2019, 173, 399-414. [CrossRef]

5. PIANC (MarCom Working Group 30). Joint PIANC-IAPH Report on Approach Channels-Preliminary Guidelines: Supplement to Bulletin No. 87; PTC2 Report of WG 30; PIANC General Secretariat: Brussels, Belgium, 1995.

6. MOTC (Ministry of Transport of China). Code for Master Design of Ship Locks. JTJ 305-2001; Standardization Administration of China: Beijing, China, 2001.

7. Ji, U.; Jang, E.-K.; Kim, G. Numerical modeling of sedimentation control scenarios in the approach channel of the Nakdong river estuary barrage, South Korea. Int. J. Sediment Res. 2016, 31, 257-263. [CrossRef]

8. Xu, J.; Li, Y.; Xuan, G.; Melville, B.W.; Macky, G.H. Numerical simulation of turbidity current in approach channels with a closed end. J. Waterw. Port Coast. Ocean Eng. 2020, 146, 04020036. [CrossRef]

9. Zheng, S. Reflections on the Three Gorges project since its operation. Engineering 2016, 2, 389-397. [CrossRef]

10. Li, W.; Wang, D.; Yang, S.; Yang, W. Three Gorges project: Benefits and challenges for shipping development in the upper Yangtze river. Int. J. Water Resour. Dev. 2020, 1-14. [CrossRef]

11. Briggs, M.J.; Borgman, L.E.; Bratteland, E. Probability assessment for deep-draft navigation channel design. Coast. Eng. 2003, 48, 29-50. [CrossRef]

12. U.S. Army Engineer Waterways Experiment Station. Spillway and Lock Approach, Jim Woodruff Dam, Apalachicola River, Florida, Hydraulic Model Investigation; Technical Report No. 2-340; U.S. Army Engineer Waterways Experiment Station: Vicksburg, MS, USA, 1952.

13. Franco, J.J.; McKellar, C.D. Navigation Conditions at Maxwell Locks and Dam, Monongahela River, Hydraulic Model Investigation; Technical Report No. 2-672; U.S. Army Engineer Waterways Experiment Station: Vicksburg, MS, USA, 1965.

14. Davis, W.G.; Davidson, R.A. Melvin Price Locks and Dam Auxiliary Lock and Rotary Lock Culvert Valve, Mississippi River, Alton, Illinois, Hydraulic Model Investigation; Technical Report HL-91-5; U.S. Army Engineer Waterways Experiment Statio: Vicksburg, MS, USA, 1991.

15. Stockstill, R.L.; Park, H.E.; John, E.; Hite, J.; Shelton, T.W. Design Considerations for Upper Approaches to Navigation Locks; U.S. Army Engineer Research and Development Center: Vicksburg, MS, USA, 2004. 
16. Maeck, A.; Lorke, A. Ship-lock-induced surges in an impounded river and their impact on subdaily flow velocity variation. River Res. Appl. 2014, 30, 494-507. [CrossRef]

17. Xie, M.; Zhou, J.; Li, C.; Lu, P. Daily generation scheduling of cascade hydro plants considering peak shaving constraints. J. Water Resour. Plan. Manag. 2016, 142, 04015072. [CrossRef]

18. Ardizzon, G.; Cavazzini, G.; Pavesi, G. A new generation of small hydro and pumped-hydro power plants: Advances and future challenges. Renew. Sustain. Energy Rev. 2014, 31, 746-761. [CrossRef]

19. Couto, T.B.A.; Olden, J.D. Global proliferation of small hydropower plants-science and policy. Front. Ecol. Environ. 2018, 16, 91-100. [CrossRef]

20. Kuriqi, A.; Pinheiro, A.N.; Sordo-Ward, A.; Garrote, L. Water-energy-ecosystem nexus: Balancing competing interests at a run-of-river hydropower plant coupling a hydrologic-ecohydraulic approach. Energy Convers. Manag. 2020, 223, 113267. [CrossRef]

21. Poff, N.L.; Zimmerman, J.K.H. Ecological responses to altered flow regimes: A literature review to inform the science and management of environmental flows. Freshw. Biol. 2010, 55, 194-205. [CrossRef]

22. Hayes, D.S.; Brandle, J.M.; Seliger, C.; Zeiringer, B.; Ferreira, T.; Schmutz, S. Advancing towards functional environmental flows for temperate floodplain rivers. Sci. Total Environ. 2018, 633, 1089-1104. [CrossRef] [PubMed]

23. Suwal, N.; Huang, X.; Kuriqi, A.; Chen, Y.; Pandey, K.P.; Bhattarai, K.P. Optimisation of cascade reservoir operation considering environmental flows for different environmental management classes. Renew. Energy 2020, 158, 453-464. [CrossRef]

24. Bravo, H.R.; Jain, S.C. Flow fields in lower lock approaches induced by hydro-plant releases. J. Waterw. Port Coast. Ocean Eng. 1991, 117, 369-389. [CrossRef]

25. Li, F.; Yang, W.; Dai, H. Research on the influence of unsteady flow produced by operation of TGP on navigation III: Lower Yichang reach of Gezhouba project. J. Hydroelectr. Eng. 2006, 25, 56-60.

26. Yang, W.; Sun, E.; Rao, G.; Wang, X. Research on the influence of unsteady flow produced by operation of TGP on navigation II: Reach between TGP and Gezhouba project. J. Hydroelectr. Eng. 2006, 25, 50-55.

27. Zhao, J.; Zhao, S.; Cheng, X. Impact upon Navigation Conditions of River Reach between the Two Dams by Peak Shaving at Three Gorges Hydropower Station. In Proceedings of the 2012 International Conference on Modern Hydraulic Engineering, Nanjing, China, 9-11 March 2012; Procedia Engineering: Amsterdam, The Nederlands, 2012; pp. 152-160.

28. Shang, Y.; Li, X.; Gao, X.; Guo, Y.; Ye, Y.; Shang, L. Influence of daily regulation of a reservoir on downstream navigation. J. Hydrol. Eng. 2017, 22, 05017010. [CrossRef]

29. Liu, Y.; Chen, S.; Huang, W.; Ma, G. Discussion of "Influence of daily regulation of a reservoir on downstream navigation" by Yizi Shang, Xiaofei Li, Xuerui Gao, Yanxiang Guo, Yuntao Ye, and Ling Shang. J. Hydrol. Eng. 2018, 23, 07018010. [CrossRef]

30. Jia, T.; Qin, H.; Yan, D.; Zhang, Z.; Liu, B.; Li, C.; Wang, J.; Zhou, J. Short-term multi-objective optimal operation of reservoirs to maximize the benefits of hydropower and navigation. Water 2019, 11, 1272. [CrossRef]

31. Peng, W.; Fengshuai, C.; Xin, X. Yangtze river: China's golden waterway. Proc. Inst. Civ. Eng. -Civ. Eng. 2010, 163, 15-18. [CrossRef]

32. Chaudhry, M.H. Open-Channel Flow; Prentice-Hall: Englewood Cliffs, NJ, USA, 1991.

33. Kuiry, S.N.; Pramanik, K.; Sen, D. Finite volume model for shallow water equations with improved treatment of source terms. J. Hydraul. Eng. 2008, 134, 231-242. [CrossRef]

34. Erpicum, S.; Pirotton, M.; Archambeau, P.; Dewals, B.J. Two-dimensional depth-averaged finite volume model for unsteady turbulent flows. J. Hydraul. Res. 2014, 52, 148-150. [CrossRef]

35. Zhao, D.H.; Shen, H.W.; Tabios, G.Q., III; Lai, J.S.; Tan, W.Y. Finite-volume two-dimensional unsteady-flow model for river basins. J. Hydraul. Eng. 1994, 120, 863-883. [CrossRef]

36. Sleigh, P.A.; Gaskell, P.H.; Berzins, M.; Wright, N.G. An unstructured finite-volume algorithm for predicting flow in rivers and estuaries. Comput. Fluids 1998, 27, 479-508. [CrossRef]

37. Moriasi, D.N.; Arnold, J.G.; Liew, M.W.V.; Bingner, R.L.; Harmel, R.D.; Veith, T.L. Model evaluation guidelines for systematic quantification of accuracy in watershed simulations. Trans. ASABE 2007, 50, 885-900. [CrossRef]

38. MTPRC (Ministry of Transport of the People's Republic of China). Navigation Standard of Inland Waterway; GB 50139-2014; MTPRC: Beijing, China, 2014. 
39. Niu, X. Key Technologies of the hydraulic structures of the Three Gorges project. Engineering 2016, 2, 340-349. [CrossRef]

40. Qin, P.; Xu, H.; Liu, M.; Du, L.; Xiao, C.; Liu, L.; Tarroja, B. Climate change impacts on Three Gorges reservoir impoundment and hydropower generation. J. Hydrol. 2020, 580, 123922. [CrossRef]

Publisher's Note: MDPI stays neutral with regard to jurisdictional claims in published maps and institutional affiliations.

(C) 2020 by the authors. Licensee MDPI, Basel, Switzerland. This article is an open access article distributed under the terms and conditions of the Creative Commons Attribution (CC BY) license (http://creativecommons.org/licenses/by/4.0/). 